NIST GCR 14-979

\title{
Community Resilience Workshop July 30, 2014
}

David R. Mizzen

Peter J. Vickery Francis M. Lavelle Applied Research Associates, Inc.

Kent $\mathrm{Yu}$ SEFT Consulting Group

http://dx.doi.org/10.6028/NIST.GCR.14-979

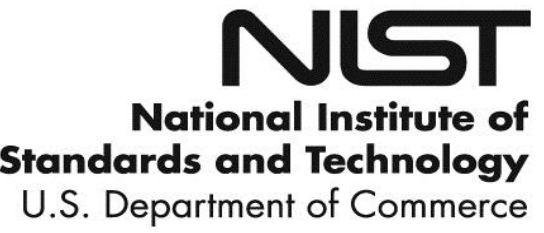


NIST GCR 14-979

\section{Community Resilience Workshop July 30, 2014}

Prepared for U.S. Department of Commerce Engineering Laboratory National Institute of Standards and Technology Gaithersburg, MD 20899

David R. Mizzen

Peter J. Vickery Francis M. Lavelle Applied Research Associates, Inc.

Kent $\mathrm{Yu}$ SEFT Consulting Group

http://dx.doi.org/10.6028/NIST.GCR.14-979

September 2014

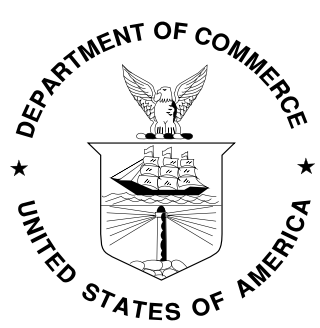

U.S. Department of Commerce

Penny Pritzker, Secretary

National Institute of Standards and Technology Willie E. May, Acting Under Secretary of Commerce for Standards and Technology and Acting Director 
This publication is available free of charge from: http://dx.doi.org/10.6028/NIST.GCR.14-979

This publication was produced as part of contract SB1341-13-CN-0084 with the National Institute of Standards and Technology. The contents of this publication do not necessarily reflect the views or policies of the National Institute of Standards and Technology or the US Government. 


\section{Acknowledgements}

The workshop held at the Stevens Institute of Technology on July 30, 2014 was organized by the National Institute of Standards and Technology (NIST) to inform the development of the Disaster Resilience Framework currently under development.

The workshop and this subsequent report benefitted from the efforts of many individuals. First, we would like to thank Dr. Michael Bruno and his colleagues at the Stevens Institute of Technology for their hospitality in hosting the workshop. The authors of this document would also like to express their gratitude to the following individuals, who made significant contributions to the planning, organization, and execution of a successful workshop:

Tonia Bohnen, Advanced Innovations and Marketing, LLC

Stephen Cauffman, NIST

Erica Kuligowski, NIST

Therese McAllister, NIST

Nancy McNabb, NIST

The authors are also grateful to their team members and additional NIST staff who participated by assisting in development of the breakout sessions, authoring chapters of the $25 \%$ draft of the framework, and collecting input from the stakeholder during the breakout sessions:

Erin Ashley, URS

Jason Averill, NIST

Millie Glick, NIST

Howard Harary, NIST

Jeffery Kotcamp, TRC Solutions

Robert Pekelnicky, Degenkolb Engineers

Chris Poland, Chris D. Poland Consulting Engineer

Karen Reczek, NIST

Adrienne Sheldon, URS

Scott Tezak, TRC Solutions

Kent Yu, SEFT Consulting Group

The facilitators who led the breakout sessions did an excellent job of leading the discussions, collecting information and transcribing the stakeholder input into the tables presented in this workshop summary. We would like to thank them all for their efforts and professionalism:

Fred Hansen, Energetic Incorporated

Katie Jereza, Energetics Incorporated

Mauricio Justiniano, Energetics Incorporated

Tommi Makila, Energetics Incorporated

David Martin, Energetics Incorporated

Joan Pellegrino, Energetics Incorporated

Stephanie Shuff, Energetics Incorporated

Ann Terranova, URS 
The workshop benefitted from an interesting panel session and keynote address. We are thankful to the following individuals for sharing their insightful input with the participants who attended:

Stephen Flynn, Northeastern University Meghan McPherson, Adelphi University

Shivendra Panwar, New York University Polytechnic School of Engineering Alexandros Washburn, Stevens Institute of Technology

Rae Zimmerman, New York University

Most importantly, the authors are thankful to all of the participants who attended the workshop. Well over 100 participants attended the workshop and provided input based on their expertise. The workshop would not have been a success without you. We look forward to your continued input at future workshops. 


\section{Community Resilience Workshop Stevens Institute of Technology \\ Hoboken, NJ \\ July 30, 2014}

\section{Meeting Summary}

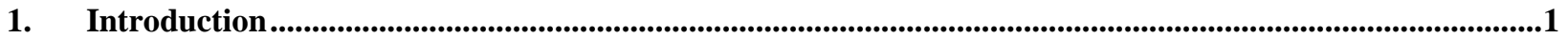

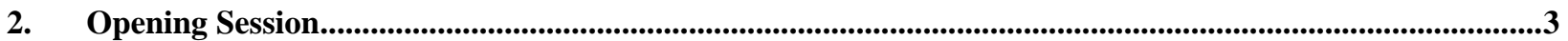

3. Panel Session - Resilience Lessons Learned for the next Hurricane Sandy ...................................................11

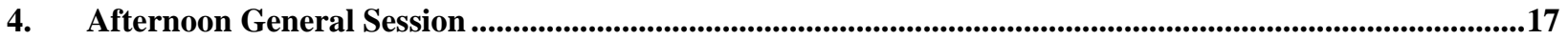

5. Breakout Session \#1: Framework Chapter 2 - Community Disaster Resilience for the Built

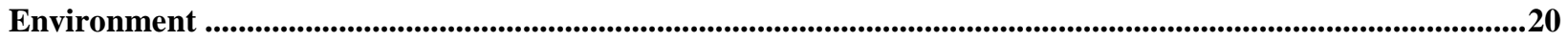

6. Breakout Session \#2: Framework Chapter 5 - Buildings and Facilities Sector .............................................29

7. Breakout Session \#3: Framework Chapter 6 - Transportation Sector ................................................................36

8. Breakout Session \#4: Framework Chapter 7 - Power/Energy Sector..................................................................45

9. Breakout Session \#5: Framework Chapter 8 - Communication and Information Systems Sector ............54

10. Breakout Session \#6: Framework Chapter 9 - Water and Wastewater Sector ............................................62

11. Breakout Session \#7: Disaster Resilience Standards Panel Charter...................................................................74

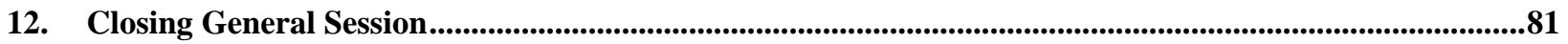




\section{Introduction}

Presidential Policy Directive 21 defines resilience as the ability to "prepare for and adapt to changing conditions and withstand and recover rapidly from disruptions." Many communities have developed disaster response plans to prepare for disaster events that will help save lives, protect property and limit the economic damage. However, disaster resilience also includes determining vulnerabilities, improving performance of the built environment during a disaster event, and minimizing the recovery times and economic losses.

Buildings and lifelines (transportation, water, energy and communications) play an important role in any community. Historically, buildings and lifelines have been designed and treated as separate entities without much consideration for one another. However, as has been seen in recent events, such as Superstorm Sandy, Hurricane Katrina, and the Joplin Tornado, the interdependencies of buildings and lifelines play a huge role in the ability of a community to recover in both the short and long term.

To address this problem, the National Institute of Standards and Technology (NIST) is leading a team to convene quarterly workshops in different regions of the country to inform the development of a comprehensive, community-based disaster resilience framework. The goal of the workshops is to engage a diverse group of stakeholders from across the country and obtain

their input for the development of the framework. Version 1.0 of the Disaster Resilience Framework will provide regional, state, local and tribal authorities with a general framework of codes, standards, available tools, and best practices to plan for and support community resilience. NIST will be convening a Disaster Resilience Standards Panel (DRSP) in 2015 to expand on and refine Version 1.0 of the framework. The DRSP will also develop Model Resilience Guidelines to catalogue best practices and state of the art in resilience.

The first stakeholder workshop was held at the NIST Gaithersburg, MD Campus to kick-off the development of the framework. The second workshop, which is summarized in this document, was held at the Stevens Institute of Technology in Hoboken, NJ on July 30, 2014. Between the first and second workshops, a 25\% draft of the Disaster Resilience Framework was developed and posted to the NIST website for stakeholders to review prior to the workshop. The Hoboken, $\mathrm{NJ}$ workshop served as the first of a series of workshops to obtain input from stakeholders on a working draft of the framework.

Figure 1 shows the agenda for the July $30^{\text {th }}$ NIST Community Resilience Workshop held at the Steven's Institute of Technology in Hoboken, NJ. This document provides a summary of the content from the July $30^{\text {th }}$ workshop and input collected from the stakeholders. 


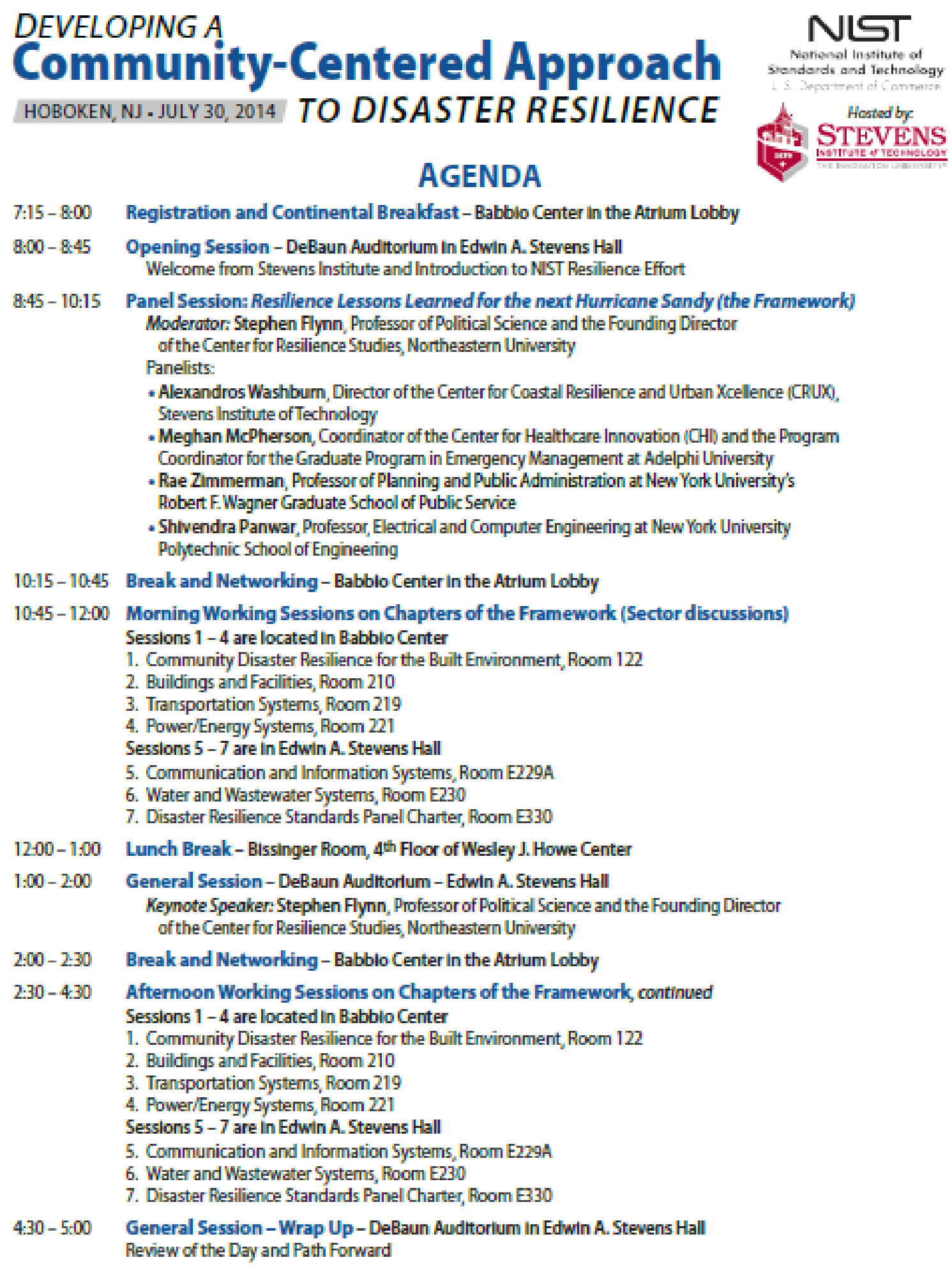

Figure 1. Agenda for July $30^{\text {th }}$ NIST Community Resilience Workshop 


\section{Opening Session}

The Opening Session for the Second Stakeholder Workshop of the NIST Community Resilience Program began at 8:00 a.m. Mr. Stephen Cauffman of NIST provided introductory remarks and welcomed the participants. The following is the prepared text of Mr. Cauffman's remarks:

Welcome to the Second Stakeholder Workshop for the NIST Community Resilience Program where we will be discussing the topic of resilience and the development of a communitycentered framework for resilience. For those of you who participated in the first Disaster Resilience Workshop in April, you will see that a fair amount of progress has been made in the development of the Disaster Resilience Framework since then. This is the first of a number of working meetings in which NIST and its team are looking for input on the draft framework.

Mr. Cauffman then introduced Dr. Michael Bruno, the Dean of Stevens Institute of Technology. The following is the prepared text of Dr. Bruno's remarks:

Welcome to the Stevens Institute of Technology. I would like to provide some history about Stevens Institute for those of you who are not familiar with Hoboken and the Stevens Institute of Technology. America's, arguably, first family of inventors, the Stevens Family, purchased the island of Hoboken following the Revolutionary War.

Hoboken, and Stevens Institute, has a long history of innovation dating back to the early 1800s, when the first steam powered ferry was launched by Colonel John Stevens and his sons in 1804. When Thomas Jefferson was President, the Stevens family worked with Congress to create patent law to protect the intellectual property of their inventions, relating mostly to their work in the transportation industry. The result was that the United States of America was the first country in the world to provide protection for intellectual property.

Edwin Stevens founded the Stevens Institute of Technology in 1870 and created the first School of Mechanical Engineering. The American Society of Mechanical Engineers was also founded here. This spirit of innovation is still held by the Stevens Institute of Technology today. We continue to be very involved in sciences, engineering, architecture, and security.

Stevens Institute of Technology hosted a two-day workshop with the sole purpose of defining resiliency. It was found during the workshop, as is still the case today, there is little agreement on the definition of resilience. With respect to the Marine Transportation System, resiliency denotes a system that is able to withstand disruption and still provide a minimally acceptable level of service. However, if you cannot withstand a disruption and then come back to a greater level of resilience, then you are not achieving resiliency. Thank you and welcome to the Stevens Institute of Technology. 
Mr. Cauffman then introduced Dr. Howard Harary, the Acting Director of the Engineering Laboratory at NIST, where this resilience program is housed. Below is the prepared text of Dr. Harary's remarks:

Good morning. My name is Howard Harary and I am the Acting Director of the Engineering Laboratory at NIST, and we are sponsoring this second workshop on disaster resilience. Welcome! I especially want to thank the Stevens Institute of Technology, and Dr. Bruno, for hosting this event.

It is altogether fitting that we hold the workshop here at the Stevens Institute, and in particular the city of Hoboken. As many of us are well aware, the community of Hoboken was severely impacted by flooding during Superstorm Sandy. In the immediate aftermath of the storm, many Stevens Institute students volunteered their time to provide relief assistance to the local community. In addition, Stevens Institute faculty members contribute to the body of knowledge to understand and mitigate the numerous challenges posed by climate change. And, the Department of Homeland Security's Center for Maritime, Island, and Remote and Extreme Environment Security is co-led by the Stevens Institute of Technology. Stevens' focus within the Center is on port security.

So, while disaster resilience is of great importance to the local community here in Hoboken, and to the Stevens' Institute of Technology, disaster resilience is also of significant national importance.

In 2011, the latest year for which we have complete data, there were 14 weather and climaterelated events that each caused more than $\$ 1$ billion in damages. Total property damage exceeded $\$ 55$ billion. These events included tornadoes, hurricanes, wildfires, heat waves, droughts, blizzards, and other severe weather. The following year, Superstorm Sandy caused more than $\$ 65$ billion in damages and economic losses. So, I'm sure we can all agree that it's imperative that we work together towards reducing the impact of natural and man-made hazards in terms of both cost and the time to recover. And, as we do that we also need to account for the changes in hazard exposure from climate change. It is past the time to realize that it's no longer sufficient to build based on historical hazard exposure. The environment is changing.

We must build, and if necessary rebuild, based on the projected exposure during the life of the facility. And as much as resilience is a matter of protecting lives and property, it is also a matter of rapidly restoring the ability of our communities to resume normality following a disruptive event.

Resilience is also about ensuring the continued competitiveness of U.S. businesses and industry. The administration has made adaption to climate change a priority, and the President's Climate Action Plan, released last summer, covers the actions the federal government is taking to address the effects of climate changes. The plan has highlighted the need to make our nation's communities better prepared to adapt to changing conditions and to withstand and recover rapidly from disruptions. Many federal agencies are working on resilience, and I'm pleased to see that a number of them are represented here today. 
As one of these federal agencies, the Department of Commerce has made resilience a high priority. The Secretary of Commerce included resilience in the Department's Strategic Plan. In this context, our colleagues at NOAA have been active on many fronts, including Weather-Ready Nation, coastal resilience, as well as improved warnings for severe weather. The Commerce Department's Economic Development Administration is also engaged given their role in supporting economic development in communities. So, in the end, what are we trying to accomplish here? We are focused on the notion that planning for resilience centers on the consideration of the social functions that sustain a community, and that the built environment, buildings and infrastructure, play in supporting those functions.

Social functions include government, business, industry, and individual citizens. Performance of the built environment for resilience requires understanding the interdependencies that exist among buildings and infrastructure systems, the importance of the buildings and infrastructure to the social function of the community, and when these functions must be restored to support recovery and a sustainable future.

Currently, there are no generally accepted, science-based means to achieve these objectives, although there is excellent work being done within the federal government, academia, and at the state and local level to advance resilience concepts. The NIST initiative that we're here to advance today will address these issues by providing an overall framework for disaster resilience, guidance to achieve the goals established in the framework, science-based tools to assess resilience at the community scale, and economics-based tools to support decision making at the community level, all together aimed at enhancing community resilience. To accomplish this, we need your help as community resilience stakeholders.

The first component of our initiative is the development of the Disaster Resilience Framework. The framework is being informed by a series of stakeholder workshops. You're here at the second one today. As we progress, working drafts of the framework are being posted on our website and your comments are welcome at any time. In the long-term, there is an opportunity to participate in the Disaster Resilience Standards Panels. This will be a stakeholder organization that will further develop and expand the framework, and develop model resilience guidelines.

The planning for the formation of the Disaster Resilience Standards Panel will begin today in one of the breakouts as the groups begin discussing the panel's form and how it should be organized. In parallel with this effort, we are also embarking on a research program to develop models to assess the effects of disruptive events on buildings and infrastructure, and the social systems they support. We will develop science-based tools to assess resilience at the community scale and economics-based tools to assist decision-makers in planning investments to enhance resilience.

NIST is augmenting the expertise of its team with a number of Disaster Resilience Fellows. These Fellows will support the creation of the draft Disaster Resilience Framework. A second group of Fellows, following on next year, will support the research program.

Lastly, NIST recently announced a Federal Funding Opportunity for a new Disaster Resilience Center of Excellence. The idea of these Centers is to quickly augment the depth and breadth of NIST's capacity and capability in areas of national importance. This will be a $\$ 4 \mathrm{M}$ per year program lasting five years, with an option to extend for another 5 years. The 
Disaster Resilience Center will focus on three research topics: 1) A computational modeling environment for community resilience, 2) Data management tools for community resilience systems, and 3) Resilience data architecture validation studies.

In closing, this is an exciting time to be working on a topic so critical to our nation's future. I am truly pleased that you have taken time out of your busy schedules to contribute to this effort. I wish you all a productive workshop and look forward to working with all of you in this important effort. Thanks, and get to work!

Mr. Cauffman then provided background to the participants on the NIST Community Resilience Program. Below is the prepared text of Mr. Cauffman's remarks:

[The slides referenced in the following text are located on the NIST.gov website.]

As Howard mentioned, this is a large national problem, especially economically. The current approach we take of response and rebuilding is inefficient for dealing with natural disasters. We don't account for the interconnectedness of buildings and infrastructure or the effect of social institutions. More importantly, we don't really take into account climate change. We typically take a historical approach.

Dr. Bruno was correct in stating that the definition of resilience is difficult to agree on. For the purposes of this program, we are going to use the definition from Presidential Policy Directive-21: Resilience is the ability to prepare for and adapt to changing conditions and the ability to withstand and recover rapidly from disruptions. In the context of community resilience, the emphasis is not only on mitigating risk, but implementing measures to ensure that the community recovers to normal, or near normal function, in a reasonable timeframe.

If you think about the community, you have the social systems on one side, (left side on the slide 4 presented), including citizens, government, industry and business. These social needs drive the functional requirements for the physical environment. That is, buildings and infrastructure. If we look at the physical assets, we can think of it as a system of buildings and infrastructure. There are forces that act against the community, including natural hazards such as wind storms, fires, etc. Manmade hazards can also lead to stress being put on the built environment. We are not addressing the problem of aging infrastructure in this effort, but degradation is certainly a negative factor in terms of the infrastructure being able to withstand extreme loads. Climate change is also a forcing function proving to have a significant impact on the performance of a community's infrastructure. To offset that, we can establish more advanced performance goals for the built environment. We can take mitigation actions and plan to make improvements for response and recovery.

For this part of our program, NIST is convening highly diverse stakeholders interested in developing the first version of a comprehensive Disaster Resilience Framework for achieving community resilience that considers the interdependence of the community's physical and human assets, operations, and policies and regulations. We want to establish a Disaster Resilience Standards Panel to further develop the Disaster Resilience Framework for the next 
version, Version 2.0. We are using a model that was developed by the Smart Grid program, and the panel there has become very active to address inoperability. It has developed working groups to address the various issues and we envision taking a similar approach for the Disaster Resilience Standards Panel. The panel will also develop Model Resilience Guidelines, in the longer-term, for critical buildings and infrastructure systems essential to community resilience based on model standards, codes, and best practices.

Stakeholder involvement is critical to the success of this effort. For NIST, this is expanding well beyond our usual stakeholders. We typically work with codes and standards, engineers and other practitioners. We are going well beyond this to work with state, local, and regional officials, and the insurance and re-insurance industries among many others.

The entire federal government has been tasked with coming up with climate adaptation strategies for their individual departments. The Department of Homeland Security, National Science Foundation, and many others are currently, or are becoming, heavily involved in resilience, and investing very heavily in these efforts.

The Disaster Resilience Framework focuses on the role the built environment plays in ensuring community resilience. We want to establish types of performance goals and ways to express them for buildings and infrastructure systems. We have an ongoing, parallel effort to identify existing standards, codes and best practices that address resilience. We also want to identify gaps that must be addressed to achieve resilience and capture the regional differences in perspectives on resilience through these workshops.

The Disaster Resilience Standards Panel (DRSP) will represent the broad interests of the stakeholder community. It will be open to anyone who is interested and will ideally become a self-governing entity. They will work to further the Disaster Resilience Framework and develop the Model Resilience Guidelines.

The first workshop was held on April $7^{\text {th }}$ at the NIST Gaithersburg, MD, campus to kick-off the development of the Disaster Resilience Framework. The goal of the next three workshops is to use working sessions to focus on developing the Disaster Resilience Framework and lay the groundwork to establish the Disaster Resilience Standards Panel. The April 2015 workshop will be organized around the release for public comment of the draft Disaster Resilience Framework and the formal establishment of the Disaster Resilience Standards Panel. Participation in all workshops is open to anyone who is interested.

In terms of progress, we have released a $25 \%$ draft. In October, we will provide an updated $50 \%$ draft followed by a $75 \%$ draft in January 2015 . It will still have some gaps at that point, but it will be a much more mature draft. We will then release the draft framework for public comment at the April workshop.

To participate, attending the workshops is important. We will announce the release of chapters prior to each workshop and welcome your review of the drafts posted on the website. Please share your knowledge and expertise as well as make others aware of this program, including the framework, panel, and workshops.

If you would like to contact me, you can do so via email (stephan.cauffman@ nist.gov or resilience@nist.gov) or phone (301-975-6051). Our website will also be updated regularly and is the source of a lot of useful information for this program 
(http://www.nist.gov/el/building materials/resilience/).

Mr. Cauffman was followed by Dr. Therese McAllister who provided information with regards to the plan for the day. Below is the prepared text of Dr. McAllister's remarks:

[The slides referenced in the following text are located on the NIST.gov website.]

Good morning. I would like to talk more about the details of what we will be doing today. You all should have received a handout with an agenda for the day and a map. Following this introductory session, Steve Flynn will lead a panel discussion that includes four excellent speakers with different perspectives on community resilience. Following the panel session, we will go back to the Babbio Center for a half-hour break and then will convene for our morning breakout sessions, which will last for a little more than one hour.

At the end of the morning sessions, we will have lunch, followed by Steve Flynn's keynote address. We will then reconvene in the same breakout sessions for the afternoon. Hopefully, at that point, everyone will be comfortable in their groups and we can really dig into the framework to get input.

There is an entire team behind the effort of the development of the framework. NIST staff, chapter authors, and our conference planner and facilitators, [slide 3], are all here and will be present in the breakout groups to collect your input. The map on your agenda shows the buildings we will be using today. The Babbio Center is where you registered this morning. We are currently in Stevens Hall, and lunch will be held in the Howe Center.

You each selected a breakout session and we have tried to put you all in your first choice. The color tab on your name tag represents the breakout session to which you have been assigned. Some of the breakout sessions are in the Babbio Center, (Community Disaster Resilience, Building and Facilities, Transportation Systems, and Power/Energy Systems), and others, (Communication and Information Systems, Water and Wastewater Systems, and the DRSP Charter), are here in Stevens Hall.

This slide, [slide 6], shows the outline of the draft framework. The first two chapters focus on the social aspects of the community and performance goals from a community perspective. Chapters 5-9 focus on the individual sectors, (buildings, transportation, energy, communication and information systems, and water and wastewater systems), which will be a large focus of the workshop today. The last two chapters will lead us towards identifying and developing tools and metrics that can be used for evaluating community resilience.

Today we will focus on Chapters 2, 5, 6, 7, 8, and 9, in addition to the Disaster Resilience Standards Panels Charter.

For the next workshop, which will take place on October 27-28 in Norman, Oklahoma, we will continue to address these chapters as well as those for the social needs of the community, (Chapter 1), as well as Interdependencies and Cascading Effects, (Chapter 4). When we refer to cascading effects, we are talking about failures that lead to unforeseen 
consequences and additional downtime which is much greater than what was anticipated. The last chapter, (Chapter 10), will identify tools and metrics that can be used to evaluate disaster resilience at the community level. We have started looking at tools and metrics. It has been observed that there are some tools and metrics available for evaluating disaster resilience, but they are generally qualitative rather than quantitative. One thing that NIST would like to do in the long-term is develop science-based tools and metrics.

Our goals for today are to develop awareness of community issues rather than sector or owner issues, and identify topics that need to be added or better addressed to achieve community resilience. These are still early drafts and so we think there is a lot of room for improvement. We really want to hear from you, the stakeholders, about the interests and issues that you would like to see included/addressed in the framework for community resilience. This will allow us to develop a much stronger document as we move forward.

Looking at the specifics, we want to know what tools are needed by people, business, and government to achieve resilience. We are going to focus on recovery today: both the degree of recovery and the amount of time needed for recovery. Many events in recent years have shown that recovery is not guaranteed, such as Hurricane Katrina, Hurricane Sandy, some of the tornadoes in the Midwest, and the earthquakes in Christchurch, New Zealand and Fukushima, Japan. Some communities have recovered, while others have not. We want to know why there is such a wide range of recovery levels, (and success). This will help us identify issues that communities need to address to make themselves more resilient.

Community resilience is the ability to return to full occupancy and function as soon as needed to support a well-planned and expedited recovery. We need to establish transparent hazard definitions, performance measures for the built environment and restoration goals that support response and recovery.

In your breakout groups, (for the chapter specific breakouts), each participant will receive a sheet with the proposed definition hazard and performance levels. To be resilient, you need to go beyond just one hazard level. The "routine" hazard is an event in which buildings and systems should be capable of remaining fully operational and not experience any significant damage. The "expected" event is based on the design level normally used for buildings. For this level of hazard, buildings and systems should remain functional at a level sufficient to support the response and recovery of the community. An "extreme" event is the maximum considered hazard level and reflects changes anticipated due to climate change. In an extreme event, critical facilities and infrastructure should remain functional, while other buildings and infrastructure should perform at a level that protects occupants and allows them to evacuate safely. Emergency response plans should be planned for this level of event. We need to plan for events beyond the design level because we must be concerned with risk moving forward. It is not a matter of "if" things will fail, it is a matter of what will fail and when. We need to plan for those failures and be prepared to recover from them successfully in a timely manner.

We also need to think about what level of damage is acceptable. The definitions we are providing are based on work done in the seismic community. Category A refers to buildings that are safe and operational. We would like our critical facilities, such as hospitals, to perform at this level. Category B refers to safe and usable during repair. In this case, we would be able to tolerate some damage as long as the building is usable. Category $\mathrm{C}$ is safe and not usable. This would be a building where there is significant damage, but people are 
able to survive and evacuate after a disaster. However, people would not be allowed back in until it is repaired. The last category, Category D, is what we do not want to see. Category D buildings will have partial or complete collapse, which often occurs in buildings that would not meet current design standards, such as unreinforced masonry walls in seismic or tornado prone areas/regions.

We want to use the recovery levels to help define the performance goals/criteria of our infrastructure (other than our buildings). Category I is defined by $100 \%$ recovery of services within days. Category II indicates $90 \%$ recovery within weeks and $100 \%$ recovery within months. Category III allows for $90 \%$ recovery within months and $100 \%$ recovery within years. As we have seen with many recent events, it is often the case that our infrastructure falls into Category III. Is this acceptable? Are we happy with that kind of performance?

All hazards are part of community resilience. We do not want to address just one type of hazard, but want systems to become resilient to all of the applicable hazards they may be subjected too.

The Recovery Matrix shows the routine, expected, and extreme events. As a community, we want to define what kind of recovery times we want for each level of hazard for the different systems of infrastructure we have in our community, whether it is roads, power, buildings, water, etc. This framework should be used to start thinking through this process.

Today, we want to advance the content of the framework using your input, and get you really engaged so you want to continue participating in the workshops and become interested in participating as a member of the Disaster Resilience Standards Panel.

With that, I would like to thank you for your time, and the next step will be to begin the panel session. 


\section{Panel Session - Resilience Lessons Learned for the next Hurricane Sandy}

Dr. Stephen Flynn of Northeastern University moderated the panel session, which included presentations with different perspectives on resilience from Mr. Alexandros Washburn of the Stevens Institute of Technology, Ms. Meghan McPherson of Adelphi University, Dr. Rae Zimmerman of New York University, and Dr. Shivendra Panwar of the New York University Polytechnic School of Engineering.

The first panel member to speak was Mr. Alexandros Washburn. The following is the prepared text of Mr. Washburn's remarks:

[The slides referenced in the following text are located on the NIST.gov website.]

Good morning and thank you very much. I will be speaking to you from the perspective of an architect, a professor, and someone who experienced the flooding of Hurricane Sandy.

First, I would like to speak about our Coastal Resilience and Urban Excellence (CRUX) Center. CRUX is a research and education center dedicated to the proposition that coastal cities can increase their resilience to climate change while simultaneously improving their quality of life.

The reason I left the Bloomberg administration was because of what happened after Hurricane Sandy. I experienced it as a regulator during the day and a resident at night and it was an eye-opening experience. The City of New York, which had an excellent administration, did not have all of the data, tools, and understanding to handle that magnitude of disaster. That is what brought me to Stevens Institute - it has the ability to improve our understanding and bring together all of the key elements in understanding the problems.

CRUX believes that resilience and quality of life can best be achieved in coastal cities by combining three disciplines: 1) Hydrodynamics - understanding the force of the water; 2) Urban Design - Understanding the force of the city; and 3) Complex Systems Understanding the population response. If we can bring together these three characteristics in models, we will make tremendous progress addressing resilience.

I operate from the framework that is laid out in a book I wrote that was released in October called The Nature of Urban Design, which was sponsored by the Rockefeller Foundation.

I look at resilience primarily through the lens of risk because my house was flooded. I look at risk in terms of the equation:

Risk = Probability $\mathrm{x}$ Consequence

I work on adaptation so the consequences can be reduced, and thus the risk. This leads to my definition of resilience, which is the actions that can be taken to reduce risk. I model this in the equation:

Risk $=($ Probability - Mitigation $) \times($ Consequence - Adaptation $)$

Adaption includes social cohesion, emergency planning, economic diversity, fortification, 
resistance, and retreat.

Data is needed to manage problems. You must be able to understand and know what you are dealing with in terms of a disaster type and magnitude in order to model it. When modeling and thinking about resilience, we want to make sure that we come back, (after a disaster), to a level better than when we started. We have to look at resilience as an opportunity to improve the state of our infrastructure.

My home was flooded in Hurricane Sandy and we lost power since the electrical panels were in the basement. In the days and weeks following, I tried to come up with ways to make my home flood proof. However, everything I was proposing violated the building code, the zoning code, the National Flood Insurance Program (NFIP), etc. If I took the path of least regulatory resistance, I could make a resilient home. However, if my entire community did that, it would not be a resilient community because it would negatively impact businesses, interaction of people, etc. So, we need to incorporate the thinking that just because one thing may be good for an aspect of a community, it may also cause negative impacts. The need for flexibility for pilots is needed to experiment and understand how buildings and infrastructure will behave in situations where we do not have enough information. Typically, though, we converge on standards that do not allow for this experimentation.

If we can combine the technical and qualitative aspects in our approach, I think we will be able to make our communities resilient, and improve our quality of life. Thank you very much.

The second panel member to speak was Ms. Meghan McPherson. The following is the prepared text of Ms. McPherson's remarks:

[The slides referenced in the following text are located on the NIST.gov website.]

Good morning everyone. This morning I am going to talk about the energy sector and my experience in Hurricanes Katrina, Sandy, and Irene, and ice storms.

Most infrastructure sectors are very reliant on the energy sector. Therefore, it is important to look at the energy sector and ensure it is included in any resilience framework or assessment.

As was seen in Hurricane Sandy, there is a high level of energy concentration in the northeast, right where we were hit. As a result, we had a lot of problems during and after the storm.

When considering electric power, we need to think about delivery, including generation, substations, transformers, and poles. For deliverable fuels, we need to look at natural gas, home heating oil, diesel, kero-based, mixed use as heating fuels in colder climates, jet fuel, petroleum, and refineries. We also need to consider nuclear generated power.

I was asked to speak about my experience with Hurricanes Katrina and Sandy. They are difficult to compare because of the complexity of systems in the different areas. However, Katrina was a Category 3 storm when it made landfall, whereas Sandy was a Category 1 
storm when it made landfall. Their durations over land were both about the same: Katrina was 33 hours and Sandy was 32 hours. One important commonality is that they both had compounding storms. Hurricane Katrina was followed by Hurricane Rita a month later and Hurricane Sandy was followed by a winter storm about one week later. When we look at the interdependencies and cascading effects, this is where we can really run into problems.

When we are talking about the resiliency of the energy sector, Long Island has a lot of high elevations in the middle, whereas New Orleans is the opposite - it is essentially a bowl. Topography is something that needs to be considered in resilience planning for communities.

Looking at the Long Island Power Authority service maps, [slide 7], we can see the progression of power restoration after Sandy. Most people think that rural areas take the longest to have their power restored. However, from my experience with Katrina and Sandy, I can tell you that the most populous areas take the longest to have their power restored because everything is packed in tight and other things need to be fixed first.

In Louisiana, a similar power restoration example is shown, [slide 8]. This shows the effects of both compounding storms with different trajectories, (Katrina and Rita), and, again, that the compact areas of infrastructure have longer recovery times.

One of the most important things is that we need to build, (and rebuild), in a smart way. After Katrina, we did some smart things and other things that were not so smart. In New Orleans, it was the areas that were most densely populated that did not return quickly.

We also have to consider gas restoration. If you look at the map on this slide, [slide 10], where gas was out, electricity was on. We have to deal with cases like this as well. Aging infrastructure is a big issue as well. The public housing area of New Orleans had a very aged infrastructure and was still not restored 3 years after the storm. When we rebuild, we need to be aware of the aging infrastructure.

We also have to consider gasoline. In Long Island, we did not have gasoline in the New York/New Jersey area. There were gas stations that had gas but no power, and others that had power but no gas. Many people were lined up for gasoline for their generators so they could stay warm since it was a cold time of the year. The State of Georgia came up with a clever way to determine which gas stations have gas and power, which was important for deployment of emergency vehicles. The state placed all of their lottery machines in gas stations, and could therefore see which stations were operable.

The framework does talk about ice, which needs to be considered. We talk a lot about wind and flooding, but ice is also a potential problem. This slide, [slide 13], shows the change of climate is also impacting recovery times and performance. Therefore, the combination of aging infrastructure and changing climate is leading to more problems.

From an individual perspective, we need to look at restoration timeline versus capacity and preparation for longer restoration. From the community side, we need to look at codes, transportation and transmission of supply, including deterioration and upgrading, and refineries and platforms. We also need to look at our security and vulnerabilities from an all hazards perspective and include allowances for climate change. From a policy standpoint, we need to identify legal authorities, waivers, the Jones Act, and the Strategic Petroleum 
Reserve. Thank you very much for listening.

The third panel member to speak was Dr. Rae Zimmerman. The following is the prepared text of Dr. Zimmerman's remarks:

[The slides referenced in the following text are located on the NIST.gov website.]

Good morning. I will be speaking about the framework for transportation relating to Hurricane Sandy. I will also be talking about vulnerabilities and relationships with the energy sector and other sectors.

Looking at NOAA's tropical cyclone return period in years, [slide 3], we can see that the return periods in more southern states are lower. However, even in the northeast, we have return periods of 25-50 years.

There are many drivers to transportation vulnerability. According to the U.S. Bureau of the Census, four of the five New York counties rank the highest among U.S. coastal counties in changes in population density from 1960-2008. So when an event takes place, a lot of people get hit in these areas.

The second challenge is that we are using a lot of energy, which is in turn driving up production. As a result, private vehicle transportation use is increasing. We are traveling increasingly despite increases in fuel cost. We are also using public transportation massively in the tri-state area. The tri-state urbanized area had 4.18 billion passenger trips in 2012 , more than six times the next largest urbanized area in population. The ridership accounted for 22 billion passenger miles over the course of that year.

Our infrastructure is not in great shape. All of the transportation infrastructure was at best graded as a "C" by the American Society of Civil Engineers (ASCE). About two dozen bridges have collapsed in the U.S. as reported by the National Transportation Safety Board (NTSB) since the mid-1960's. Bridges that have collapsed have generally been younger in age than the overall bridges in the US even though bridge condition generally declines with age. For example, while $30 \%$ of the bridges that collapsed were under 20 years old, only $20 \%$ of all bridges were in that age category. A combination of causes usually contributes to bridge collapses, though there may be a single initiating event. Non-redundant design, common in the mid- $20^{\text {th }}$ century, can contribute to the severity of consequences of bridge collapses.

Debris accumulation and flooding had the largest effects, (from Hurricane Sandy), on transit. In the couple of weeks following Hurricane Sandy, about $80 \%$ of the transit lines fully recovered along their entire lengths, and the rest allowed for partial coverage of routes. Compared with the same period in the previous year in the second week of 2012 following Hurricane Sandy, the overall system ridership declined an average of 14-16\%.

In the 2003 northeast U.S. and Canada blackout, transit took about 1.3 times and traffic signals 2.6 times as long to be restored once electric power returned. The Metro-North 
railway, (between New York and Connecticut), experienced an outage of more than a week due to the impairment of a large power line. Transformer explosions have impaired transit lines, (e.g. NYC on July 21, 2001), and power outages have caused closures of San Francisco Bay Area and Chicago transit lines.

Electric power is moving towards a lot of solutions. After Sandy, Con Edison is taking on an effort to harden their infrastructure by sealing components, submerging critical components, removing components, and decentralizing energy systems.

We can also use green infrastructure to pull a lot of water away from our transportation systems. Other examples of techniques to absorb water include raising subway grates and street furniture, building elevation/barriers for transit gates to divert water, and building roadside swales for water diversion. White roofs are also helpful as an adaptive measure for heat retardation in transit systems. Solar roofs can also be used.

We need to have flexibility through multi-modal connections. For example, having bus connections at subway stations in New York City would be useful. Connections with buses do and can continue to provide alternative transportation modes in emergencies. The New York City subway stations vary in the number of buses stopping at the stations from a couple of dozen to none. Bus connectivity is in part related to the number of train tracks located at each station.

We can redesign our street systems. Locally, we can use innovation to overcome problems relating to the environment, security, etc. Streets and rail corridors are key platforms for change.

I think the framework sets a good foundation to attack a lot of these issues and will become supplemented by the interdependencies. Thank you.

The final panel member to speak was Dr. Shivendra Panwar. The following is the prepared text of Dr. Panwar's remarks:

[The slides referenced in the following text are located on the NIST.gov website.]

Thank you, Steve, and thank you to NIST for organizing this event and to Stevens Institute for hosting it. I always tell my students and anyone who will listen that the one piece of telecommunications equipment that you should hang onto is your landline telephone, which does not need external power to function. Following Sandy, my landline did not work, and my cellular phone had very limited functionality - only text messaging worked.

Before Sandy, I was looking at what would happen if AT\&T and T-mobile merged. Mergers like this are happening in Europe and all over the world. This is happening due to business reasons such as increasing capacity. However, we can also consider what the resilience benefits are for mergers. Mergers allow for sharing infrastructure or sharing surviving infrastructure, sharing spectrum, increasing or maintaining capacity, reduce vulnerability, better service following outage events, and better reliability. 
Traditional roaming works when no connection is available to the assigned operator. For example, this happens when you leave the country. You connect to a different carrier. Typically, this has many constraints and can result in high service charges. This concept can be extended to improve resilience. One scenario is that users could freely access the service towers of either operator by the "strongest signal-first" rule. The principle of increased service through sharing can be extended to a neighborhood femtocell "connectivity island" based on subscribers with backup power supplies and functioning ISPs. This assumes that femtocells can at least temporarily be opened to subscribers to competing carriers.

This slide [slide 4] shows the locations of base station carriers, (cell towers), for two major service providers in Washington, DC. As you can see, they are not co-located, which can be a good thing for resilience. As an example, in a situation where there is no cooperation between carriers, poor service can be an issue depending on your location from your service provider's nearest cell tower. However, when service providers do cooperate and share infrastructure, you will be able to have access to the strongest signal available. The capacity is quadrupled, per customer capacity is doubled. Conversely, you can lose up to half the cell towers without a reduction in per customer capacity, (i.e., you can maintain the same level of service as before merger even if you lose half of your towers). After a disaster, this would help improve the level of service.

We will skip over some of the technical details and get right to the conclusions. A simple cooperation policy with modest changes to existing networks can achieve large capacity gain. Network capacity after a merger of two identical carriers quadruples the capacity as compared to a single operator. Therefore, in the future, we need to have more cooperation strategies, encourage load balancing and energy efficiency, and need to learn how to share the profits and the costs so that resilience can be implemented in a competitive market.

We held a Resilient Network Workshop at NYU Poly. It was held under Chatham House rules with participants from industry, government, and academia. It was found that there was a need for coordination and cooperation between utilities and government, and a need for a common geographical recovery database. Diversity in technology helps with uncertainty. The use of wireless, wireline, two-way radio, satellite phones, etc. gives you options and ways to communicate if one mode of communication is lost. We also talked about the use of battery operated customer premise equipment, prioritized hardening of key buildings needed for recovery, and sensors and social networks for monitoring. Thank you. 


\section{Afternoon General Session}

The keynote speaker for the afternoon plenary session was Dr. Stephen Flynn of Northeastern University. The following is the prepared text of Dr. Flynn's remarks:

\section{[The slides referenced in the following text are located on the NIST.gov website.]}

I would like to thank NIST for giving me the opportunity to speak at this important workshop. One thing I learned early in my career was that you are not going to beat Mother Nature. We need to manage risk because you are never going to eliminate it.

As Steve Cauffman mentioned this morning, there are many different definitions for resilience. Presidential Policy Directive 21 provides a good definition that you can see here, and that is: "The term resilience refers to the ability to prepare for and adapt to changing conditions and withstand and recover rapidly from disruptions. Resilience includes the ability to withstand and recover from deliberate attacks, accidents, or naturally occurring threats or incidents."

Tom Friedman of the New York Times provided an interesting perspective of the change in mindset in an article on May 24, 2014. He stated, "the abiding strategy of our parents' generation was containment of communism in order to be free. The abiding strategy of our generation has to be resilience. We will only be free to live the lives we want if we make our cities, country, and planet more resilient."

As the world continues to grow and change, we face a number of challenges that add to our risk and potential problems. We now have more users, and that results in pushing/exceeding infrastructure design capacity. As we all know, infrastructure without adequate investment in maintenance and repair increases risk. The rising urbanization, particularly in coastal areas with substantial exposure to the effects of climate change, and external shocks for naturally occurring and man-made sources increase the risks to infrastructure. Finally, the absence of political will for undertaking the advanced planning and long-term investment in building, upgrading, and adequately maintaining infrastructure in a major obstacle. We need to facilitate and encourage an emphasis on bolstering the resilience of critical infrastructure. In summary, we as a generation have inherited our parents' mansion, and we are failing to keep it up.

For Hurricane Sandy, I like referring to it as a "predictive surprise" because we know it is coming, but we don't know the timing of the event and we, as a community, act as though it is surprising. We can predict these events, just not the timing. When you look at the path and size of Hurricane Sandy, you can see that even though the wind was not severe, the storm surge being pushed by the wind was a massive risk. I think people are used to thinking of hurricanes in terms of wind speed rather than storm surge and that may have thrown people off and left them poorly prepared for Sandy.

Stevens Institute actually modeled a storm surge event prior to Sandy and combined it with GIS technology to show the potential impacts of flooding on Hoboken, NJ. This [slide 12] was then shown to the mayor and support staff to help them make decisions with regards to 
evacuation, etc.

As an example of comparative resilience, we can see how two different companies in New York City protected their building, (their assets), for Hurricane Sandy. Goldman Sachs surrounded the entire building with 15 feet of sand, whereas Citigroup only provided minor protection at their opening doors [slide 13]. Keep in mind that these buildings are about three blocks apart; they had the same information, but used it in very different ways.

As you can see in this slide [slide 14], the protection for the Goldman Sachs building worked well. It was one of the only buildings in Manhattan with power. However, because the transportation system was not functional, there were no employees and, thus, they were shutdown anyway. There was also little to no ability to telecommute due to region-wide power outages. The key point of this is that even though the company did all the right things, the loss of functionality ends up halting operations anyway. This is a real challenge even for the most sophisticated corporations with a lot of resources.

We want to move towards a resilience-centric approach rather than a threat-centric approach. We need to distinguish between critical processes, essential function and full/normal function. Based on that, we need to identify and adopt resilience design features, processes, and protocols that mitigate risk of disruption, and speed recovery when mitigation measures fail. Some of the ingredients of resilience design options include: 1) Cushionability graceful degradation of non-essential function during periods of stress; 2) Resistance redirecting threat/hazard away from essential function; 3) Robustness - harden critical processes and essential function; 4) Redundancy - have spares to provide critical processes and essential function; and 5) Graceful extensibility - the capacity for the infrastructure to adapt to deal with an uncertain future risk environment.

To put resilience into practice, we have to model before the event occurs. We must have resilient design, have contingency plans and exercises, and maintain situational awareness. During the event, we need to be resourceful in our decision making so as to mitigate consequences and support rapid recovery. After events, we need to restore critical processes and essential function, restore full/normal function, and learn from our mistakes, adapt and improve the resilience of our designs.

For resilience, the goal is to maintain function, not just protect the asset. In the case of a bridge, the function is mobility. We want to see disasters and rebuilding as an opportunity to improve resilience. Another option is to prepare ahead of time for recovery and let failures occur, with rapid response and recovery being the focus. Others will make some improvements as to reduce the damage/failures, but will take some time to recover because there is no response/recovery plan. The worst case, which is often that of small businesses across the country, is when there is no preparation, the event comes and there are failures. Then, since there are essentially no resources, it takes a very long time to recover.

Resilience can also be a deterrent. Resilience reduces risk by undermining the threat. This relationship can be presented as:

Threat $=$ Intent $\mathrm{x}$ Capability

Less vulnerability can translate into elevating the requirement that an adversary possesses more capability to overcome safeguards. Less consequence will undermine intent, (i.e., there 
is little motivation for carrying out an attack if it does not achieve mass destruction and disruption). We do need to expect some loss of functionality, and we need to address problems beforehand and have a plan for relief.

For some events, we only want the professional to deal with the situation after a disaster. In some cases, we also need to harness the capabilities of volunteers.

In conclusion, resilience requires greater emphasis on and investment in forecasting, modeling, monitoring, and assessment capabilities that can support mitigation, speedy response and recovery, and inform adaptation in the aftermath of disruptive incidents. Largescale disasters impact regional systems and, therefore, require an enhanced capacity for undertaking preparedness, response, and recovery at a regional level. Resilience also requires a deeper understanding of interdependencies and the cascading effects that a major disruption can generate. Companies and communities need to "bake-in" resilience into their critical systems and functions. When disasters strike, the first responders are always local, and citizens are indispensible strategic assets. Finally, local, regional, and national competitiveness will increasingly be defined by the level of resilience that communities and countries have to withstand, nimbly respond, and rapidly recover from shocks and disruptive events. People will choose to invest in companies and live in areas that possess resilience and gravitate away from those that do not. There is a competitive advantage to live in communities that are resilient. Thank you very much. 


\section{Breakout Session \#1: Framework Chapter 2 - Community Disaster Resilience for the Built Environment}

Both a morning, (10:45 a.m. - noon), and afternoon, (2:30 - 4:30 p.m.), session were held to get input from the stakeholders in attendance regarding Community Disaster Resilience for the Built Environment, Chapter 2 in the existing $25 \%$ draft framework.

The breakout session began with the Energetics Incorporated facilitator asking the group to introduce themselves, their affiliation and reason for attending the workshop. Mr. Chris Poland, the author of the chapter, then introduced himself and provided background for the chapter, and the framework as a whole, as well as set the tone for the questions to be asked and reinforced that his main goal was to collect input that could be incorporated into the next draft of the framework. The first question asked of the group was a typical brainstorming question to engage the stakeholders/participants. The question asked, regardless of what was included in the $25 \%$ draft of the framework, was:

"Who should define the performance goals and make the decision for a community or regional disaster resilience plan?"

As recorded by the Energetics facilitator, Table 1 shows that the breakout group agreed that the stakeholders of the community need to participate in defining the performance goals for a disaster resilience plan. Participants identified political officials/leaders, engineers, builders, developers, real estate and other professionals as members of the community who should be included in developing the overarching performance goals of a community. 


\section{Table 1. Parties Responsible for Defining Performance Goals of Community and Regional Disaster Resilience Plans}

\section{Q1: Who should define the performance goals and make the decision for a community or regional disaster resilience plan?}

- The community in a participatory governance process

- Leaders - local official owner/operators

- Public/private partnership

- Identification of public gaps

- Business back to business

- What is in it for me?

- A coalition of professional, academic and community leaders coordinated by a facilitator (like you)

- Mayor's office $\leftarrow \rightarrow$ City's OEM $\leftrightarrow \rightarrow$ Industry specific $\leftrightarrow \rightarrow$ People and businesses $\rightarrow$ Decision, $\leftarrow$ Feedback

- Engineers

- Are communities discussing their resiliency plans with neighboring communities - regional considerations

- Whole community PPD-8

- A body of representatives that can ensure both a survivor centric approach and including the whole community

- Each community should be able to weigh different goals among a defined set of goals

- SOPA Senior Officer Present Afloat (strongest form of "local" government)

- Stakeholder committees (akin to NY Community Reconstruction Program)

- Coalition of government agency representatives in utilities (electric, water) infrastructure (roads, buildings, planning) and private industry in these areas

- Builders, developers, real estate prof.

The second question asked of the participants was:

"What key elements and characteristics would you find to be the most useful in a Disaster Resilience Framework that is intended to guide community planning for disaster resilience?"

As can be seen in Table 2, the participants provided a lot of good, and varied, input in response to this question. It was felt that direction needs to be provided in terms of a communication structure, meaning that leadership needs to know who should talk with whom to maintain governance and recovery momentum after a disaster event. Participants also want to have mitigation plans available that can be easily implemented. Along the same lines, participants would like to have a catalogue of best practices to help with implementation of the framework and grid maps of neighborhoods/communities/regions so that their connections can be understood and vulnerabilities can be identified. It is also important to identify vulnerable populations who may need extra attention and assistance following a disaster event, including the ill, low-income, and elderly.

The participants felt it was essential to build a desire to succeed so that cooperation between sectors and key stakeholders is attainable. There also needs to be a common vision of the end state for communities so everyone has goals to strive towards. Outreach will be needed to educate communities, stakeholders, and decision makers of the goals of the framework and implementation because this shift in thinking will be difficult to instill in these people and their communities. 
Table 2. Key Elements and Characteristics for Disaster Resilience Framework

\section{Q2: What key elements and characteristics would you find to be the most useful in a Disaster Resilience Framework that is intended to guide community planning for disaster resilience?}

- Build desire to succeed

- Evacuation plan

- How to get out

- Where to go

- Living knowledge base (and Virtual Stakeholder Table)

- Define and prioritize the basic hierarchy of needs

- Build

- Decision support tools for leadership

- Consider time of recovery, against?

- Essential functions

- Identification of

- Funds

- Budget line item

- A common vision of state of the community $\mathrm{x}$-days/months/years after event

- An understanding of the weakest "links" in an infrastructure and/or social system

- References list for resources

- Leadership and inspiration apply to recovery

- Communication structure - who should talk with who

- Is there a mitigation plan in place?

- Recovery location information for government and public

- Physical phone tree
- Set of best practices for private developers on resilient land development practices (community design, earth moving, infrastructure)

- Grid map overlay of region define connections/vulnerability

- Identification and a plan for vulnerable and medically fragile members of the community

- A compendium of relevant codes and standards by situational use areas

- Beds for critical personnel

- A communication network that is flexible to alternate evacuation/rescue/recovery plans

- Flood-protection system performance data to direct responses to critical areas

- Dynamic and broad education component for all children in the community

- Flexibility. Sector specific list with key tips for private businesses to employ flexibility in operations to minimize business interruption

- Ability to predict (model), prevent (designs), assess (measures), mitigate, restore (react)

- Effective use of social networking tools
- Eliminating the need for (horizontal) evacuation

- Inventory of stuff

- Regional network for coordinating cross jurisdiction issues

- Are there existing networks with different levels of government and among different stakeholders

- Suite of indicators in place so they know where they are going

- Economic tools for mitigation implementation

- Many cold war "resiliency" measures have led to long-term damage (highways $\rightarrow$ sprawl, supermarkets $\rightarrow$ food waste)

- Assessment of roadway and other transit conditions and update schedule

- Is there a disaster debris management plan in place and do folks know/understand its implementation?

- Does the community have a sense of its interconnectedness to other surrounding communities?

- Are there alternative transportation modes in place if roads are flooded?

- Has the community considered the placement of trees in juxtaposition and power lines?

The third question asked of the group was:

"What new/updated/improved standards, codes, models, practices, thresholds/performance goals, and guidance are needed to support effective disaster resilience in your community?"

The responses given by the participants were categorized into: 1) goals and metrics, 2) knowledge, information, guidance, 3) models and practices, 4) codes and standards, and 5) other needs. The extent of input captured by the facilitator is included for the first three categories in Table 3 and the remaining categories are shown in Table 4. 
Table 3. New/Updated/Improved Goals and Metrics, Knowledge, Information, Guidance, Models and Practices Need to Support Disaster Resilience

Q3: What new/updated/improved standards, codes, models, practices, thresholds/performance goals, and guidance are needed to support effective disaster resilience in your community?

\begin{tabular}{|c|c|c|}
\hline $\begin{array}{c}\text { Needs re: Goals \& } \\
\text { Metrics }\end{array}$ & $\begin{array}{l}\text { Needs re: Knowledge, } \\
\text { Information, Guidance }\end{array}$ & $\begin{array}{c}\text { Needs re: Models \& } \\
\text { Practices }\end{array}$ \\
\hline $\begin{array}{l}\text { - Assessment tools. } \\
\text { Interoperability tools and } \\
\text { mechanisms (e.g., fusing } \\
\text { two comm. Infrastructures) } \\
\text { - Community metrics that } \\
\text { capture the social or quality } \\
\text { of life aspect } \\
\text { - Criteria (or to do lists) for } \\
\text { Performance-Based } \\
\text { Planning approach } \\
\text { - Performance objectives - } \\
\text { occupancy specific } \\
\text { - Post-Event - Metrics to } \\
\text { identify condition of } \\
\text { building or hospital or } \\
\text { equipment or any structure } \\
\text { - Proper economic } \\
\text { assessment of disaster - } \\
\text { beyond "short-term" } \\
\text { - Tracking of costs } \\
\text { - Road repair } \\
\text { - Public transit } \\
\rightarrow \text { to inform better } \\
\text { allocation of funds } \\
\text { - Resilience star rating } \\
\text { program }\end{array}$ & 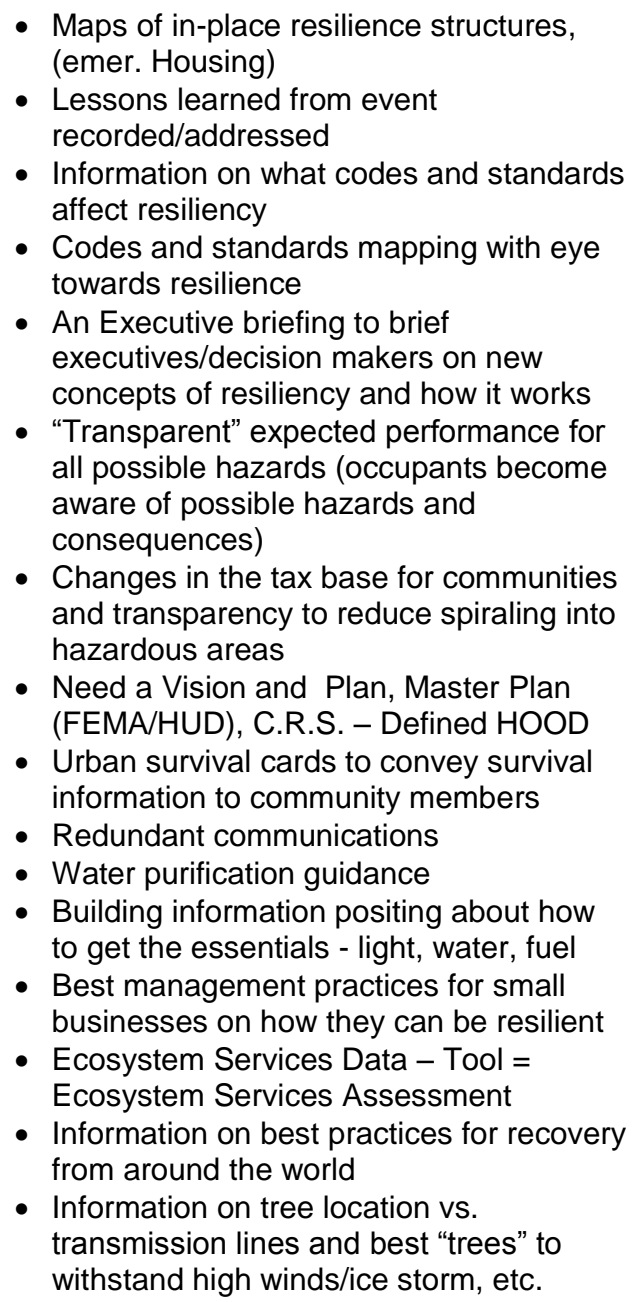 & $\begin{array}{l}\text { - Begin to develop vision - } \\
\text { decisions now affect community } \\
\text { for DECADES } \\
\text { - Public private partnership } \\
\text { - Business buy-in } \\
\text { - Economic recovery strategies } \\
\text { - Information sharing } \\
\text { - Regional integration } \\
\text { - Decision-support-tools to aid } \\
\text { prioritization } \\
\text { - Scenario specific } \\
\text { - Consequences specific } \\
\text { - Built on time of recovery } \\
\text { - Establishment of a financial } \\
\text { model for recovery } \\
\text { - Motivate private sector by an } \\
\text { incentive driven approach to be } \\
\text { resilient } \\
\text { - Supply chain models - global } \\
\text { (multi-scale modeling problem) } \\
\text { - Role of distributed infrastructure } \\
\text { systems in community resilience } \\
\text { (water, energy, food distribution, } \\
\text { housing) } \\
\text { - Borrow/adapt ideas from nuclear } \\
\text { regulatory commission for design } \\
\text { of infrastructure (risk-informed } \\
\text { decision making) } \\
\text { - Comprehensive models to answer } \\
\text { "What if . . ?" questions based on } \\
\text { understanding of decision } \\
\text { progress and their impacts } \\
\text { standards }\end{array}$ \\
\hline
\end{tabular}

The goals and metrics discussed by the group included assessment tools for interoperability of systems, performance objectives, and post-event rating of condition of buildings and equipment. The group also wanted proper economic assessments that go beyond the short-term to capture the whole picture. This would include tracking repair costs and public transit, (either loss of, or expanded use of), for evacuations. Creating programs like the Resilience Star Rating Program was also thought to be useful. 
In terms of knowledge, information, and guidance, the group felt it would be beneficial to have access to lessons learned from past events and how they were addressed. The participants want "transparent" expected performance goals for all of the different hazards a community may encounter. Again, the discussion was based around having more information to be able to make informed decisions so they can have access to the most critical utilities, including water, communications, and power.

The participants felt that more tools are needed to model the complex environment we live in today, and the models must be adaptable for future scenarios. There is also a need to develop several different types of models, including financial models for recovery, decision support tools, and global, (cross-jurisdiction), supply chain models.

Table 4. New/Updated/Improved Standards, Codes, and Other Needs to Support Disaster Resilience

\section{Q4: What new/updated/improved standards, codes, models, practices, thresholds/performance goals, and guidance are needed to support effective disaster resilience in your community?}

\begin{tabular}{|c|c|}
\hline Needs re: Codes \& Standards & Other Needs \\
\hline $\begin{array}{l}\text { - Empower and motivate Code Enforcement } \\
\text { - De-conflict Codes, e.g., generators in basement } \\
\text { - "Equitable" building codes/standards - cannot simply } \\
\text { rely on ability of owner to pay } \\
\text { - "Fortify" for N.E. beyond code - insensitive to build } \\
\text { better } \\
\text { - Revolving goals for changing circumstances } \\
\text { - Data transfer and coordination } \\
\text { - "You cannot always get what you want but just } \\
\text { - } \text { - Cometimes you get what you need" (NOLA) } \\
\text { - Structure } \\
\text { - Elec/Mech systems } \\
\text { - Building fire protection } \\
\text { - With incentives and benefits from zoning, insurance } \\
\text { - } \text { in core involvement of professional private community } \\
\text { - Code knowledge should be part of professional } \\
\text { - Comeditation } \\
\text { on potential recovery projects and related issues }\end{array}$ & $\begin{array}{l}\text { - Clearing house of online resources and real-time } \\
\text { - Inapping } \\
\text { - Housing and neighborhood should include: } \\
-1 \text { ) Major building material depots ("Lowes") } \\
\text { - } 2 \text { ) Dump zones } \\
\text { - Heed some tiering of levels: } \\
\text { - Roads } \\
\text { - Airports } \\
\text { - (Mandatory) Education and licensing to live in an at- } \\
\text { - Com region } \\
\text { - Redundancy in services but not in research/publication } \\
\text { - Long-term recovery planning should incorporate } \\
\text { "Smart Growth" principles so all efforts/resources do } \\
\text { not just address disaster event, but long-term steady- } \\
\text { - Dtate } \\
\text { - Pe-conflict recovery funding goals of federal recovery } \\
\text { funding - funding should support resiliency } \\
\text { Past environmental issues/efforts that can be } \\
\text { - Mggravated by the disaster } \\
\text { - Skywriters of dropping of leaflets to reach community } \\
\text { - "Wine and music" - resilience needs to go beyond } \\
\text { survival and provide the things that enrich life }\end{array}$ \\
\hline
\end{tabular}

The participants did not discuss specific codes and standards, but did discuss the general needs of the future direction of the codes and standards to support disaster resilience. As seen in Table 4, 
the conversation focused largely on the need for code adaption and enforcement, and the need for incentives to motivate communities to build beyond code requirements to a higher standard.

The group also discussed other needs to support disaster resilience, including building inventories for infrastructure and buildings, (some of which already exist), educating communities about the risks, and the need for "smart growth."

The next question asked of the group was:

"What are the facilities and infrastructure that we need to include in each of the clusters?"

Similarly to the previous question, the input from stakeholders was categorized. The categories used were: 1) critical response facilities/systems, 2) emergency housing and support systems, 3) housing and neighborhood infrastructure, and 4) community recovery infrastructure. The first two categories focused on immediate needs, (i.e., within 1-72 hours following an event), given their importance in the wake of a disaster. The third category focused on a timeframe of one week to two months, and the final category focused on long term recovery (three months to three years).

The participants had a lot of input in response to this question, as is shown in Table 5 and Table 6. The participants felt some of the primary needs to include in the critical response facilities/systems cluster should be communication infrastructure, critical facilities such as hospitals, flood control infrastructure such as levees and dams, power, clean water, and transportation infrastructure. It was also felt that critical response facilities should include removal of hazardous materials and a designated location to store them. 
Table 5. Facilities and Infrastructure that need to be included in Critical Response Cluster

\section{Q5: What are the facilities and infrastructure that we need to include in the clusters?}

\section{Critical Response Facilities/Systems 1-72 hours - immediate focus}

- Communication

- Internet

- Damage and hazard (cascading effects) assessment infrastructure

- Data and communications, police stations, meeting points, emergency transit/mobility, first response needs, evacuation system, shelters

- Staging areas for massive logistic support - supplies, resources, emergency workers

- Critical communications facilities (towers equipment buildings, antenna locations)

- Critical fire protection facilities

- PA systems

- Military installations

- All Regulated facilities - hospitals, utilities, airports, ports - that are required to remain operational

- Understanding function vs. structure (bridge example)

- Communications - including public to public (cell towers -text)

- Hyper local communications, should be 2-way

- Assessment tools/RA Team

- Lifelines: power, water/wastewater, communications, transportation/parts ???

- Dependencies

- Time of recovery

- Flood-control infrastructure (levees and dams)

- These might be hazard dependent

- Key is to remove further risk

- Emergency power stations

- Microgrids
- Ad Hoc communication infrastructure

- Emergency rooms, pharmacies

- Alternative transportation

- Helpline

- Social media

- Critical response should also focus on removing further risk - this may involve relocation off grid; implies a need for a shelter network

- Zero hour: identify potential places, spaces, to be used for housing shelters, etc.

- Help Center

- Communication - multi-lingual - enable community

- Charging stations

- Critical response should include removal of hazardous materials and a place to store them

For the emergency housing and support systems cluster, the immediate needs identified by the participants included debris/recycling centers, food distribution centers, emergency power stations, and emergency/temporary housing.

When discussing the housing and neighborhood infrastructure cluster, the group quickly agreed that buildings such as daycare, places of worship, food distribution centers and businesses should be included.

For the community recovery infrastructure, (i.e., for longer-term recovery), the group did not focus solely on the physical infrastructure directly, but also focused on the social needs that drive the needs for the built environment. Participants discussed the need to rebuild to a higher standard after a disaster to become more resilient. The group also suggested that groups could be formed to stay in place following future disasters to aid in both the short and long-term response. 
The need for cleanup of debris, both on land and in water, (i.e., water pollution), was also identified as a requirement for long-term recovery.

Table 6. Facilities and Infrastructure that need to be included in Clusters

\section{Q6: What are the facilities and infrastructure that we need to include in the clusters? (continued)}

\begin{tabular}{|c|c|c|}
\hline $\begin{array}{c}\text { Emergency Housing and Support } \\
\text { Systems } \\
1-72 \text { hours }\end{array}$ & $\begin{array}{l}\text { Housing and } \\
\text { Neighborhood } \\
\text { Infrastructure } \\
1 \text { week - } 2 \text { months }\end{array}$ & $\begin{array}{l}\text { Community Recovery } \\
\text { Infrastructure } \\
3 \text { months }-3 \text { years }\end{array}$ \\
\hline $\begin{array}{l}\text { - Disaster debris/recycling centers } \\
\text { - Food distribution centers } \\
\text { - Nursing homes, waste management, } \\
\text { damage assessment, transitional housing, } \\
\text { utilities } \\
\text { - Maps of vacant residential dwellings } \\
\text { (emer. Housing) } \\
\text { - Age-appropriate shelter classifications } \\
\text { - Animal shelters } \\
\text { - Trans sorting (food waste collection) } \\
\text { - Recharging depots } \\
\text { - Need infrastructure to support a trade } \\
\text { system locally } \\
\text { - Cash } \\
\text { - banking capacity } \\
\text { - Infrastructure for food distribution (e.g., } \\
\text { Hunt's Point NYC) } \\
\text { - Support systems should include } \\
\text { - Local distribution centers } \\
\text { - Linked to local operators } \\
\text { - Emergency support systems needed for } \\
\text { - Cleanup } \\
\text { - Soup Kitchen (or like) } \\
\text { - Open Parties (if safe) } \\
\text { - Emergency shelter for response/recovery } \\
\text { workforce } \\
\text { - Emergency Housing Support } \\
\text { - Transition housing } \\
\text { - Workforce movement } \\
\text { - Lifeline sector support } \\
\text { - Regional alternatives } \\
\text { - Emergency Housing: } \\
\text { - Temporary shelter - "stock" before } \\
\text { event } \\
\text { - Prefab (52K Japan) with bikes and } \\
\text { offgrid }\end{array}$ & $\begin{array}{l}\text { - Daycare centers up and } \\
\text { running } \\
\text { - Houses of } \\
\text { worship/meditation/ } \\
\text { exercise } \\
\text { - Transmission pipelines } \\
\text { - Septic systems } \\
\text { - Buildings/space for social } \\
\text { services (e.g., child } \\
\text { services) and prosecution } \\
\text { activities } \\
\text { - Consideration of restoring } \\
\text { community business } \\
\text { functionality } \\
\text { - Service cultural } \\
\text { Needs/Redefine } \\
\text { - Temp/Worship } \\
\text { - Temp/Morgue } \\
\text { - Temp/Bath House } \\
\text { - Temp/Market } \\
\text { - Temp/Banks } \\
\text { - Temp/Pharmacy } \\
\text { - Business back to business } \\
\text { - Food distribution from local } \\
\text { grocery stores (location } \\
\text { known by community) }\end{array}$ & $\begin{array}{l}\text { - Social infrastructure - establish } \\
\text { networks, coalitions, working } \\
\text { groups that will stay in place for } \\
\text { the next disaster } \\
\text { - Resilient landscape } \\
\text { repair/redesign/reconstruction/ } \\
\text { repairs to domestic } \\
\text { environment } \\
\text { - Water pollution prom severe } \\
\text { flooding } \\
\text { - Air BnB for disasters } \\
\text { - Policy should be to build back } \\
\text { better } \\
\text { - Cradle-to-cradle for temp } \\
\text { housing - no debris when new } \\
\text { housing comes on line }\end{array}$ \\
\hline
\end{tabular}

At the conclusion of the afternoon breakout session, the group reviewed the questions and responses captured during the day. The group was asked to select three to five key takeaways from the session. The general consensus of the group is summarized in Table 7. 
This publication is available free of charge from: http://dx.doi.org/10.6028/NIST.GCR.14-979

Table 7. Key Takeaways from the Building and Facilities Sector Breakout Session

\section{Community Disaster Resilience for the Built Environment Breakout Session Key Takeaways}

- Interconnection between the built environment and the psycho-social aspect of recovery: Resilience planning for the built environment cannot take place in isolation. It will impact and should be impacted by the psycho-social needs of the community. Integration with other initiatives is important (to streamline the process)

- The importance of public-private partnerships and collaboration: Much of the built infrastructure is privately owned. Community resilience planning for the built environment requires private sector involvement and must therefore consider how to engage the private sector and facilitate collaborative planning and implementation across public-private sector lines.

- The high-level clusters in the Resilience Matrix held up: Participants were able to identify and differentiate facilities and infrastructure that would fall in each of the four high-level clusters (Critical Response Facilities/Systems, Emergency Housing and Support Systems, Housing and Neighborhood Infrastructure, and Community Recovery Infrastructure). These clusters, which represent general periods of time during recovery, provided a framework for people to identify priorities. 
This publication is available free of charge from: http://dx.doi.org/10.6028/NIST.GCR.14-979

\section{Breakout Session \#2: Framework Chapter 5 - Buildings and Facilities Sector}

The Buildings and Facilities Breakout Group had 21 total participants: four from government, five from non-government organizations, four consulting engineers, and eight from academia. The group's discussion during the morning and afternoon sessions focused on seven questions, the first of which was:

"What Key Elements and characteristics would you find most useful in a Disaster Resilience Framework that is intended to guide community planning for disaster resilience for the buildings and facilities sector?"

The first main area of discussion during this segment focused on the need to develop a data model or data framework that a community can use to facilitate the collection of information needed to assess vulnerabilities and restoration times for buildings and facilities for the hazard scenarios relevant to their community. There were a variety of views on how detailed or simplified the data collection should be.

A second main area of discussion during this segment was the need for performance-based resilience guidance rather than prescriptive guidance. There should be flexibility in the framework to allow communities to experiment with differing approaches to meet their performance goals.

Other broad areas of discussion included the need for incentives and regulation, (i.e., carrots and sticks), the need for neighborhood level planning, (bottom up approach), and the importance of risk communication.

In all, a total of 20 key elements and characteristics for the buildings and facilities sector of the disaster resilience framework were identified by the group. These elements are listed in Table 8 . 
Table 8. Key Elements and Characteristics for Buildings and Facilities Sector of Framework Identified by Breakout Group

\begin{tabular}{|c|c|c|}
\hline \multicolumn{3}{|c|}{$\begin{array}{l}\text { Q1: What would help you the most? } \\
\text { What Key Elements and characteristics would you find most useful in a disaster } \\
\text { resilience framework that is intended to guide community planning for disaster } \\
\text { resilience for the buildings and facilities sector? }\end{array}$} \\
\hline $\begin{array}{l}\text { - Building and context (e.g., } \\
\text { importance of boardwalks in NJ } \\
\text { post-Sandy) } \\
\text { - Invest in information collection } \\
\text { (e.g., framework should be a } \\
\text { repository for resources) } \\
\text { - Framework should contain two } \\
\text { types of data to address needs of: } \\
\text { - Occupants } \\
\text { - Structures (e.g., condition } \\
\text { assessments - how well } \\
\text { structures likely to survive) } \\
\text { - Data model for data collection; } \\
\text { framework should establish a } \\
\text { platform/opportunity for sharing } \\
\text { information and data for other } \\
\text { purposes/processes (beyond } \\
\text { resilience) } \\
\text { BIM (Building Information } \\
\text { Modeling) is an example }\end{array}$ & $\begin{array}{l}\text { - Framework = Data (for example, } \\
\text { lowest floor elevation or LFE is } \\
\text { hard to get; Framework should } \\
\text { accommodate this) } \\
\text { - Organize the Framework by } \\
\text { carrots/sticks; e.g., incentives } \\
\text { and regulatory considerations } \\
\text { - Need to start at the } \\
\text { neighborhood level (bottom up) } \\
\text { to address community level } \\
\text { needs for resilience } \\
\text { - Keep data collection simple; } \\
\text { e.g., guidance on a card for } \\
\text { responders to know what to do } \\
\text { post-disaster } \\
\text { - Know where to go for } \\
\text { information (old and new } \\
\text { construction) } \\
\text { - Framework should focus on } \\
\text { end-decision (regarding } \\
\text { resilience opportunities) and } \\
\text { collect data accordingly } \\
\text { - The Framework needs to define } \\
\text { what are the standards (for } \\
\text { resilience) } \\
\text { The process for developing the } \\
\text { Framework should demand } \\
\text { consensus }\end{array}$ & $\begin{array}{l}\text { - The Framework should define a } \\
\text { procedure for experimentation (try } \\
\text { out different approaches - not be } \\
\text { prescriptive but performance based) } \\
\text { - It should be flexible to allow } \\
\text { innovation (e.g., look at building use } \\
\text { and geography types - not "one } \\
\text { size fits all") } \\
\text { - Options for commercial structures } \\
\text { need to be different } \\
\text { - Integration with other (resilience) } \\
\text { initiatives, such as the initiative by } \\
\text { the Rockefeller Institute } \\
\text { - Vulnerability assessments should } \\
\text { be included as part of the } \\
\text { Framework } \\
\text { - Systems based (e.g., hospitals } \\
\text { and their functions) } \\
\text { - Buildings } \\
\text { - Risk assessments should also be a } \\
\text { consideration (in the Framework) } \\
\text { - Considerations for risk } \\
\text { communication should also be } \\
\text { addressed in the Framework (it } \\
\text { applies to other sectors and should } \\
\text { be addressed more globally) }\end{array}$ \\
\hline
\end{tabular}

The second question asked of the group was:

"Who should define the performance goals and make the decisions for a community or regional disaster resilience plan for the buildings and facilities sector?"

The breakout group identified at least seven entities that should be involved in setting performance goals for buildings and facilities. These entities are listed in Table 9. The group identified needs to catalog groups that produce requirements and/or guidance for particular types of facilities, (e.g., hospitals), and the need to recognize the roles of both decision makers and decision influencers. 
Table 9. Parties Responsible for Defining Performance Goals and Decision-Making for Buildings and Facilities Sector

\section{Q2: Who should define the performance goals and make the decisions for a community or regional disaster resilience plan?}

- Code writers

- Lenders (underwriters)

- Insurers

- Researchers and designers (to allow for flexibility)

- Redefine in framework; e.g., decision makers vs. influencers

- Other Federal Agencies or OFAs (e.g., Centers for Medicare/Medicaid)
- Framework needs to be clearer at the National level; not so prescriptive locally (to allow for flexibility)

- Suggest using ICC risk category models

- DHS Critical Infrastructure (CIKR) is another source for risk categories

- Look at San Francisco SPUR model and assess whether this is effective for this effort (SPUR is too seismic focused)

The third question asked of the participants was:

"At what level and sublevel within the buildings and facilities sector should we be assigning performance goals and targets for disaster resilience for the expected event? Should this be at a relatively high level, or are sublevels important? Should the same groupings be used for extreme events?"

Rather than attempt to generate an exhaustive list of sub-categories within the buildings and facilities sector during the limited amount of time available to discuss this question, the group's discussion focused mostly on the need to review previous work and the benefits of adhering to existing guidance. Table 10 lists specific suggestions provided by the group in response to this question.

Table 10. Granularity at which Performance Goals Should be Assigned for Buildings and Facilities Sector

Q3: At what level and sublevel within the buildings and facilities sector should we be assigning performance goals and targets for disaster reilience for the expected event?

Should this be at a relatively high level, or are sublevels important? Should the same groupings be used for extreme events?

- $\quad$ Suggest using ICC risk category models

- $\quad$ DHS Critical Infrastructure (CIKR) is another source for risk categories

- Look at San Francisco SPUR model and assess whether this is effective for this effort (SPUR is too seismic focused)

- $\quad$ Framework needs to be clear at the national level; not so prescriptive locally (to allow for flexibility)

The afternoon portion of the breakout session focused on the implementation of the framework. The fourth question asked of the breakout group was: 
This publication is available free of charge from: http://dx.doi.org/10.6028/NIST.GCR.14-979

"Assume that your desired end-state is a well-defined disaster resilience plan with set targets for the built environment. What do you think will be the primary barriers/challenges or difficulties to creating and executing your disaster resilience plan?"

The main areas of discussion during this segment revolved around the challenges of improving the resilience of existing buildings and facilities, the resource challenges associated with developing and executing resilience plans, the issues of risk communication and risk perception, and the difficulties associated with engaging key parties in the planning process.

Table 11 details the two dozen barriers or challenges identified by the group regarding the creation and execution of disaster resilience plans.

Table 11. Barriers/Challenges to Creating and Executing Disaster Resilience Plan for Buildings and Facilities

Q4: What do you think will be the primary barriers/challenges or difficulties to creating and executing your disaster resilience plan?

- More use of performance based designs $\rightarrow$ leading to increased flexibility

- Retrofitting old buildings (as opposed to new construction)

- Overcoming risk perceptions communication is key (e.g., visual impacts - Hoboken example)

- Need to feel urgency, placing value on risk; help to understand the relationship between risk and taking action; it's important to keep (risk and consequences) in public eye

- Verifying incentives are warranted/eligible (some people may try and "game the system")

- Change mindset that "government will fix it"

- Build back to normal not enough
- How to define codes as minimum level vs. optimal (ties into performance based approach "codes plus" example)

- Lack of advance planning

- Lack of understanding of consequences (methodology to help understand the consequence - could be addressed through the use of case studies)

- Economics - who pays for increased standards?

- Informed decisions (with regard to benefit/cost of implementing resilience measures) needed

- Lack of community capacity/resources

- Lack of communication in general

- More engagement by developers
- Timing - short attention span post disaster (urgency diminishes as time lapses)

- At the local level, building space is fragmented (multiple owners - hard to achieve consensus on resilience actions)

- Look to other countries, e.g., Japan/Star, as examples example

- Lack of flexibility (too much detail; too prescriptive in approach)

- Leadership and consensus lacking

- Lack of understanding and acceptance of roles/responsibilities

- Impediment to increased resilience where you can't get credit you receive no insurance breaks (even though resilience actions are taking place)

- Not seeing the big picture (how do individual actions fit into the overall plan - one action can make a difference)

- Regulatory restrictions (e.g., FEMA and the constraints they bring)

The following question was asked as a follow-up to question four:

"Guidance and threshold performance goals are needed to support effective disaster resilience. What new/updated/improved, codes, models, practices/guidance and thresholds/performance goals are needed to support effective disaster resilience in the buildings and facilities sector?" 
A specific code discussed by the group during this segment was the International Existing Building Code. In general, the group also identified the need for clear and consistent standards, incentives for voluntarily bringing existing buildings closer, (but not necessarily all the way), to current codes and standards, incentives for going beyond code minimum requirements in new construction, the need for inspections to verify standards and codes are being followed, and the need for updates to account for changing and/or better understood threats.

Table 12 lists seven topics discussed by the group during this segment.

Table 12. Standards, Codes, Tools and Practices Needed to Support

Disaster Resilience Planning in Building and Facilities Sector

\section{Q5: Guidance and thresholds performance goals are needed to support effective disaster resilience. What new/updated/improved, codes, models, practices/guidance and thresholds/performance goals are needed to support effective disaster resilience?}

- International Existing Building Codes (IEBC) Standards (use as a baseline and potentially improve upon them)

- Make sure houses/structures are built to existing codes (NYC example - buildings performed ok during Hurricane Sandy)

- FEMA flood maps are needed more frequently

- Need to account for sea level rise and climate change

- More clear goals and objectives/standards

- Provide more incentives to do resilience (not just a "stick")

- Lack of inspections while construction underway (due to lack of funding and expertise; politics get in the way)

- Wind driven rain research; there is a need to increase funding for this initiative

The participants were then asked a sixth question:

"What are the knowledge needs, (e.g., data information), or gaps in your community relative to disaster resilience in Buildings and Facilities sector?"

The discussion during this segment touched on a wide range of knowledge gaps with regards to improved resilience in the building and facilities sector. The discussion ranged from the relationship of resilience to other design goals, to training on how to design for resilience, to better/easier access to resilience data and information. Specific needs identified by the group are summarized in Table 13.

The final question asked of the participants was:

"What evaluation methods, specific to the buildings and facilities sector are needed to help determine effectiveness in community disaster resilience?"

This segment quickly produced a fairly long list of approaches and methods for evaluating the disaster-related performance of buildings and facilities. Several members of the group expressed a desire for case studies, best practices, and information on existing assessment tools. A listing of the specific methods mentioned by members of the group is provided in Table 14. 
Table 13. Knowledge Needs or Gaps for Disaster Resilience in the Buildings and Facilities Sector

\section{Q6: What are the knowledge needs (e.g., data information) or gaps in your community relative to disaster resilience in Buildings and Facilities sector?}

- Universal agreement or definition of resilience

- "Whole design" perspective; there needs to be a connection between energy efficiency and resiliency

- Identify what the resilience standards/data don't address (e.g., FIRMS don't address future conditions; they are based on historical data)

- More formal process to get funding to conduct Post Disaster Assessments (i.e., Mitigation Assessment Teams or MATs)

- Better dissemination of information to increase exposure, understanding (of information as it relates to resiliency)

- Lack of understanding how to design for resiliency (lack of training)

- (Lack of) Understanding of early decisions for construction and long term consequences. Need to consider choice of:

- Materials

- Design approach

- Full body of information; need to know where to get it

- Ability to rapidly assess true building conditions post disaster (need tools)

- Not enough mechanisms for risk communication

- Not enough understanding of vulnerability and risk assessments

- Not enough understanding of how Social Media can be/is applied

Table 14. Evaluation Methods Needed to Determine Effectiveness of Community Disaster Resilience for Buildings and Facilities Sector

\section{Q7: What evaluation methods, specific to the buildings and facilities sector are needed to help determine effectiveness in community disaster resilience?}

- Mitigation Assessment Teams (MATS) - building performance \& NCST studies

- Evaluate building performance data

- \$ spent after next storm

- FEMA 452 - systems (use as methodology)

- Integrated Rapid Visual Screening (IRVS) tool (DHS tool)

- Case studies - peer review

- FEMA Hazus

- Best practices

- Losses avoided for resilience

- Insurance - connect incentive to action (to reduce risk; decrease number of claims)

- Assess claims data, NFIP data

- Insurance Services Organization's (ISO) Building Code Effectiveness Grading Schedule

- CAV/CACs as part of FEMA's Community Rating System

- Mapping and layering of disaster data can help facilitate understanding of damages

- Funding source for studies on post-disaster resilience

- DSAT - Dam Sector Analysis Tool

- Google Map - Crisis MAP

- Risk MAP data; use in conjunction with risk and vulnerability analysis

At the conclusion of the afternoon breakout session, the group reviewed the questions and responses captured during the day. The group was asked to select three to five key takeaways from the session. The general consensus of the group is summarized in Table 15. 
This publication is available free of charge from: http://dx.doi.org/10.6028/NIST.GCR.14-979

Table 15. Key Takeaways from the Building and Facilities Sector Breakout Session

\section{Buildings and Facilities Breakout Session Key Takeaways}

- It will be important to fill-in the data gaps as part of the planning process, (for resilience); integration with other initiatives is important, (to streamline the process)

- Uniform benchmarks will be important, leading to consensus

- Standards need to have flexibility and provide the ability to experiment

- It will be important to coordinate efforts on resilience with other, (Federal), agencies and entities, (e.g., Rockefeller Foundation) 


\section{Breakout Session \#3: Framework Chapter 6 - Transportation Sector}

Both a morning, (10:45 a.m. - noon), and afternoon, (2:30 - 4:30 p.m.), session were held to get input from the stakeholders in attendance regarding the Transportation Sector and the existing $25 \%$ draft framework.

The Transportation Sector breakout session began with a typical brainstorming question to engage the stakeholders/participants. The question asked, regardless of what was included in the $25 \%$ draft of the framework Transportation Sector Chapter, was:

"What key elements and characteristics would you find to be the most useful in a Disaster Resilience Framework that is intended to guide community planning for disaster resilience for the transportation sector?"

As recorded by the Energetics Incorporated facilitators, Table 16 shows the breakout group had a wide range of elements/characteristics that should be addressed to guide community planning through a Disaster Resilience Framework.

One notable point that was raised early in the discussion was that guidance on pre- and postdisaster resilience is needed. FEMA has five mission areas: Prevention, Protection, Mitigation, Response, and Recovery. Resilience is not one of them. Resilience does not refer to a pre- or post-hazard condition specifically, but rather the ability of the community to withstand a disaster event and recover rapidly from a disaster. The preparation/planning for a disaster event directly impacts the resilience of a community's performance ability to recover post-disaster. The group also discussed the need for a generally accepted definition of resilience that is flexible enough to make it apply to all hazards. As was addressed in the plenary session, NIST, (and the framework), have adapted the PPD-21 definition of resilience.

Some members of the group also discussed evacuation, and thought it should be addressed in the framework. The participants pointed out that evacuation needs to consider a number of planning issues, including where residents will evacuate to and how long it will be take them to get back to their homes, the need to better understand the transportation system in evacuation so bottlenecks don't result in people being stranded. This may also include understanding where the community's vulnerable populations are and what method of transportation would be most effective in moving them out of harm's way. A major focus of the discussion was tools and metrics. The group was not in favor of a very complex tool, but rather would prefer a simple and accurate simulation tool that would allow for continuous improvement. The tools envisioned could be used for evacuation planning and during an evacuation to get real time travel information for applicable evacuation routes. Tools are also needed to quantify performance metrics and could be used to evaluate infrastructure immediately after an event or throughout the recovery process. 


\section{Table 16. Key Elements and Characteristic for Transportation Sector of Framework Identified by Breakout Group}

\section{Q1: What key elements and characteristics would you find to be the most useful in a Disaster Resilience Framework that is intended to guide community planning for disaster resilience for transportation?}

- Define optimal asset utilization

- Understand controlled movements

- How to prevent work force absenteeism pre-disaster

- Asset preservation during disaster

- Delay negative impacts $\rightarrow$ to stage transportation response needs

- Resource (assets) re-allocation post

- Need guidance on how to think about/build transportation redundancy

- Will this chapter cover evacuation?

- Notional or real example showing how a community uses the framework for transportation

- Template for setting performance targets or goals (see water/wastewater chapter)

- Add a trends/analysis on each transportation system that are at risk (risk assessment)

- Define the communication process from citizens up to leaders

- Define leaders and roles, understand resource alliances during large disasters and catastrophes

- Focus on what the system delivers people, workers, goods and the timeliness and importance of each component

- Guidance on pre and post disaster transport. Should include resilience as well as response.

- Having a plan in place, should include

- Information

- Communication

- Guidance
- Define/understand local and regional leaders, technician and local communities

- Develop/provide simple but accurate simulation tool for scenario analysis and most appropriate response(s) and promote continued improvements in the models with more data

- Develop a generally accepted definition of "resilience" that meets federal grant requirements

- Maintain emergency functions (post disaster)

- Vulnerable evacuation protection managed (pre)

- Characteristics - reflect transportation inter-modality if in a task list or check list format

- Characteristic - flexible enough to generally apply to all-hazards (natural, technological, man-made

- Obtain traveler information for regional picture of transportation system

- Awareness - what to do in the event of . . . define by system, i.e. train/highway/airport

- Have a quantitative measure of where people will want to go

- Quantitative performance metrics and associated predictive tools

- Key element/characteristic; clarity and practical application for decision makers recognizing regional differences and needs
- A guide to embed redundancy in structures

- Define vulnerabilities/weak links of key structures

- Quantitative performance goals for each sector

- Defining time required for maximum ability to withstand/recover from event

- Key element: How to know what will be damaged next? What to look for and how to measure if better filters.

- Quantifiable standards for new construction and plans for temporary replacement of failed infrastructure

- Clear decision line taking human factors into account

- Geographic understanding of damage that will lead to better communication

- Clear guidance and documentation of tools to evaluate component capabilities $\rightarrow$ both pre/post disaster

- Recognition of interdependencies/issues beyond flooding, e.g., energy

The second question asked of the participants was:

"Who should define the performance goals and make the decisions for a community or regional disaster resilience plan in the transportation sector?"

The group had a brief discussion in response to this question and agreed that oversight is needed at every level, including city, regional, state, and federal. Although it was agreed that the government would need to make the policies and decisions, the participants want these decisions to be informed by technical experts in the community. Transportation is unique in that it has 
many different possible modes and, therefore, the stakeholders and responsible parties vary depending on the mode, which was captured by the participants as shown in Table 17.

Table 17. Parties Responsible for Defining Performance Goals and Decision-Making for Transportation Sector

Q2: Who should define the performance goals and make the decisions for a community or regional disaster resilience plan in the transportation sector?

- City/regional/state level/federal oversight

- Decisions and policies taken by government informed by the technical community

- Monitors need to be aligned with what needs to be measured

- Jurisdiction codes and standards

- Local urban planners in collaboration with engineers

- Performance goals - FEMA, FTA, FHWA-FAA - disaster and granting agencies to transportation agencies

- Decisions - owners/operators

- A broad set of stakeholders should set the goals and should empower executive action at the time of the event

- Governors and gov. task forces

- Port captains

The third question asked of the group was also related to performance goals. However, the overall goal was to determine the granularity at which the infrastructure should be considered by communities in establishing their performance goals. The question asked of the group was:

"At what level and sublevel within the Transportation Sector should we be assigning performance goals and targets for disaster resilience for the expected event? Should this be at a relatively high level, or are sublevels important? Should the same groupings be used for routine or extreme levels?"

As can be seen in Table 18, the level of granularity varies depending on the type of transportation system. For example, roads should consider highways/interstates, main, (arterial), and secondary roads. However, for rail transportation, there was discussion of whether performance goals should be defined by local and regional, (i.e., type), subway and mass transit, or passenger versus freight, (i.e., function). Airports yielded a similar discussion, (define performance goals by type or function of airport). The participants also recommended that pipelines be added to the transportation section since many pipelines pass below roadways and are subject to DOT regulations. 
Table 18. Granularity at which Performance Goals should be assigned for the Transportation Sector

\section{Q3: At what level and sublevel within the transportation sector should we be assigning performance goals and targets for disaster resilience for the expected event?}

Should this be at a relatively high level, or are sublevels important? Should the same groupings be used for routine or extreme events?

\section{Note: the majority of these responses only focus on answering the first question.}

- Roads $\rightarrow$ evacuation priority/snow removal. Use

- Arterial

- Collector

- Local

- Roads/bridges: leve of importance, e.g., "if alternate route available" -> routine if not extreme

- Terminals for all modalities - water, rail, road

- Add terminals (bus, multi-lines rail)

- Keep high level by mode

- Break up airports by - Hubs

- Regional

- General aviation

- Roads

- Secondary roads

- Main roads

- Highways

- Roads for routine, expected and extreme

- Evacuation routes

- State

- Interstates
- High level performance goals:

interstates/expressways, bridges, airports, tunnel, and transit systems: open or close

- Understand volume, routes

- Ports: split out container vs. bulk ports

- Break out by accessibility

- But must be properly defined

- Sublevel: Generally transport of cargo vs. transport of people

- Road sublevel:

- Maintenance years

- Ability to reverse direction

- One-way roads

- Does redundancy exist?

- Performance for each road level and each subsystem based on nature of disaster

- Roads:

- Highways

- Bridges

- Culverts

- Transportation systems probability $\mathrm{x}$ impact $\mathrm{x}$ likelihood risk assessment

- Bridges - separate by major structural type
- Roads:

- Access to airports/ports

- Interstate highways

- State roads

- County roads (quantified in levels based on number of people)

- Combine:

- Evacuation roads

- Emergency roads (to and from hospitals)

- Major roads for restoration

- Important roads for economy

- Rail - availability of diesel engines for a particular line

- People and pets evacuation targets (all modes)

- Define by primary/secondary tertiary roads* * ranking should change according to the event

- Rail (economic impacts)

- Local transportation

- Critical shipping corridors

- All transportation infrastructure should have threshold definitions for failure

- Define Rail by where power is obtained third rail electric overheadcatenary electric
- Consider changing "rail and subway systems" to "mass transit systems" to capture light rail, bus, ferry, etc.

- Rail should be divided into local and regional rail

- Air:

- Military airports

- Heliports

- Private airstrips

- Airports

- Local

- Regional

- National

- International

- Airports - types vs. functionality usage performance metrics

- Define Intermodal terminals (port to bus, rail to port, etc.)

- Define airports using Hub and spoke model of airports. Which are hubs, which are spokes

- Ports: define by types, functionality

- Define Waterways by importance to ports

- Add Passenger ferry service sub level

- Add pipelines as a high level

- Break-bulk roll-on/roll-off (types of cap)

Once the group was done describing what they would like to see included in the framework, a discussion of the barriers/challenges of implementing the framework took place. The group was asked: 
"Assume that your desired end-state is a well-defined disaster resilience framework which enables the community to set targets for the built environment. What do you think will be the primary barriers, challenges, or impediments to creating and executing your disaster resilience framework, from a community, personal experience, regional, or national perspective?"

As seen in Table 19, there are a number of challenges that the participants anticipated in the implementation phase. The group was concerned that involving the correct stakeholders may become an issue and that buy-in from these stakeholders is needed. To do this, the solution is to get the stakeholders involved early in the process. Additionally, it was felt that many communities may not have the expertise to understand and implement the framework under development.

Table 19. Barriers/Challenges to Executing the Disaster Resilience Framework in the Transportation Sector

Q4: Assume that your desired end-state is a well-defined disaster resilience
framework which enables the community to set targets for the built environment.
What do you think will be the primary barriers, challenges, or impediments to
creating and executing your disaster resilience framework, from a community,
personal experience, regional, or national perspective?

The group also listed many of the common concerns with any new development, including cost, practicality, political environment, and willingness/resistance to change. Another concern was 
the differences in terminology between stakeholders. State and local government terminology differs, as do the language of academia and policy or decision-makers. Creating an environment where the technical terminology is the same, (or similar), may help in communicating the goals and benefits of implementing the framework or components of it. If nothing else, the group felt that common terminology would help stakeholders from the different sectors, agencies, and industries have a useful discussion of the framework in the future.

The fifth question asked of the participants was:

"What new/updated/improved standards, codes, models, practices, and thresholds/performance goals are needed to support effective disaster resilience in the transportation sector?"

The group felt that models are needed to simulate damage of infrastructure for given hazard intensities and how long the recovery process would take. This would allow the user to understand how long it would take for emergency personnel to respond, inspect infrastructure, and get the community back to normal. Furthermore, a tool should also allow the user to understand how a failure of one or multiple links or nodes impacts the entire transportation network. Participants did identify specific examples that have been included in codes and standards that could help resilience, such as updates in the American Association of State Highway and Transportation Officials (AASHTO) standards/guidelines to protect against impact, (explosive threats). A summary of all of the stakeholder input in response to this question is shown in Table 20. 


\section{Table 20. Standard, Codes, Tools and Practices Needed to Support} Disaster Resilience Planning in Transportation Sector

\begin{tabular}{|c|c|c|}
\hline \multicolumn{3}{|c|}{$\begin{array}{l}\text { Q5: What new/updated/improved standards, codes, models, practices, and } \\
\text { thresholds/performance goals are needed to support effective disaster resilience } \\
\text { in the transportation sector? }\end{array}$} \\
\hline $\begin{array}{l}\text { - Models needed to: } \\
\text { - Identify hazards } \\
\text { - Hazard intensity } \\
\text { - Spread affected community } \\
\text { - Response and damage of } \\
\text { infrastructure component to given } \\
\text { hazard intensity } \\
\text { - How long it takes to correct } \\
\text { damage } \\
\text { - How damage relates to } \\
\text { functionality of component (bridge, } \\
\text { road system)... } \\
\text { - How component damage affect } \\
\text { the transportation network } \\
\text { - How damage to transportation } \\
\text { network affects community } \\
\text { - Economically } \\
\text { - Personal safety } \\
\text { - Other networks } \\
\text { - Develop Traffic modeling - } \\
\text { evacuation } \\
\text { - Stakeholders share transportation } \\
\text { information (common platform) } \\
\text { system data to see regional } \\
\text { picture and impacts to } \\
\text { transportation systems } \\
\text { - Community specific plans } \\
\text { - Flexibility, time of day } \\
\text { Highly coordinated with clear line } \\
\text { of command and roles, actors } \\
\text { planning }\end{array}$ & $\begin{array}{l}\text { - Slack time, reserve funding, } \\
\text { propositioning of resources } \\
\text { - Maintenance of essential functions } \\
\text { - Goal: Pre-disaster } \\
\text { arrangements/contracts with trucking } \\
\text { companies and suppliers (e.g., } \\
\text { Walmart) } \\
\text { - Develop supply chain models from } \\
\text { commercial logistics adapted to } \\
\text { disasters } \\
\text { - Standards for retrofits } \\
\text { - Update codes, i.e., fire } \\
\text { - Plan for projected future conditions } \\
\text { rather than for historic conditions } \\
\text { - Buy mountain bikes for emergency } \\
\text { responders } \\
\text { - Codes/standards - material } \\
\text { compatibility of built environment } \\
\text { (transportation, fixed assets) with } \\
\text { salt water } \\
\text { - Updated codes to account for } \\
\text { additional/magnified/multi-hazards } \\
\text { (e.g., design bridges to resist fire) } \\
\text { - Standards for both new construction } \\
\text { and retrofits } \\
\text { - Effective plans for after a disaster } \\
\text { - Adoption of (and further research } \\
\text { into) "performance-based design" by } \\
\text { technical societies } \\
\text { - Decision standards/trees for } \\
\text { closures } \\
\text { - Telework options for events }\end{array}$ & $\begin{array}{l}\text { - Plan shutdowns of systems } \\
\text { before storm hits } \\
\text { - Performance goals: } \\
\text { - Time it takes to inspect } \\
\text { infrastructure } \\
\text { - Time it takes for } \\
\text { transportation system to get } \\
\text { back to normal } \\
\text { - Performance goals: } \\
\text { - Time it takes to respond to } \\
\text { disaster } \\
\text { - Performance Goal: time it takes } \\
\text { to recover to "normal" capability } \\
\text { based on type of disaster }\end{array}$ \\
\hline
\end{tabular}

The sixth question posed to the group was:

"What are the knowledge needs or gaps in your community relative to disaster resilience in the transportation sector?"

As shown in Table 21, the group responded by first discussing the need to understand the type and magnitude of the problem(s). The participants discussed the need for real time information in the immediate wake of a disaster, (or before the disaster takes place if possible), to plan for emergency response, importing of supplies if needed, evacuation, etc. In this discussion, a need for improvements in prediction of events, such as tornadoes, was identified citing that citizens often get into their automobiles in a disaster event, (including tornadoes), and are killed as a result. Moreover, the design of existing structures, such as bridges, for different natural hazards 
was identified as information that is needed for a community to adequately address resilience. For extreme events, where evacuation is necessary, the group discussed the need for real time evacuation planning models and tools. As discussed when addressing other questions, the group inquired whether evacuation planning would be specifically addressed in the framework.

Table 21. Knowledge Needs and Gaps Relative to Disaster Resilience in Transportation Sector

Q6: What are the knowledge needs (e.g., data or models or guidance) or gaps in your community relative to disaster resilience in transportation?

- What places on the roadways flood? How much and in what situations?

- Relative interdependency of systems re: goods movement between modes, within modes

- Knowledge of existing status (e.g., bridge capacity).

- Prediction of hazards (e.g., tornado).

- Research on "performance-based engineering" philosophy

- Knowledge needs - asset specific hazard models/forecasts (storm surge height, earthquake/blast effects, etc.)

- Knowledge needs - relative interdependence of trans networks - between modes, within modes, with key sectors (water, power, comms.)

- Multi modal evacuation plan

- Climate models - location and transport needs of access and functional needs populations in the community

- Climate vulnerability models (for practitioners)

- Pet evacuation best practices (question: is the transportation chapter going to address evacuation)?
- Hazard-specific effects on infrastructure (storm-surge, etc.)

- Standards for recording weather-related $\mathrm{road} / \mathrm{rail} / \mathrm{air} / \mathrm{water}$ closures

- Demand - travel time

- Preparedness

- Asset inventory (private)

- Alternate use

- What models exist for real time evacuation planning?

- Correlate actual damage levels to predictive models. Same for hazard intensities.

- How people travel especially travel behavior in an emergency (do they rely on cars)?

- Getting real-time transportation systems closure information from one source/one stop place, i.e., 511 website/phone

- Traffic flows $\rightarrow$ freight trip generation/attraction

To follow-up on question six, the final question asked of the breakout group was:

"What evaluation methods, specific to the transportation sector, are needed to help determine effectiveness in community disaster resilience?"

Given that this question was asked towards the end of the afternoon breakout session, there was only a limited amount of input gathered from the participants as shown in Table 22. The participants stated there was no accepted methodology of how to measure resiliency. However, the participants did suggest some methods of evaluation within the transportation sector, which include standards for recording weather related road/rail/air/water closures, or how quickly or costly repairs were. Some participants stated that, for transportation, a survey could be conducted to determine the public's knowledge and level of awareness of hazards as well as how they would evacuate in an emergency. It was suggested that a report card for resilience similar to the ASCE Report Card could be used as an evaluation tool. 


\section{Table 22. Evaluation Methods to Determine Effectiveness of Community Disaster Resilience Planning in the Transportation Sector}

\section{Q7: What evaluation methods, specific to transportation, are needed to help determine effectiveness in community disaster resilience?}

- Evaluation methods for effectiveness

- Current capability targets and gap assessment (targets should be set by the community)

- Determine effectiveness - for infrastructure . . . benefit/cost analysis (see FEMA HMGP Program)

- Preparedness and awareness survey

- Heat exposure of roads

- Capability targets self-set

- Economics, timescale, level of effort

- Assemble data from all (small and large scale) in a format that can be scaled up

- What are current repairs, associated costs, and timing

- Test resilience for small events, to predict outcome for larger events

- What is the value of resiliency?

- How much it will cost to make a repair

- Protection of life and livelihood. Livelihood (economically measured) given expected hazard intensity

- Prior to an event how many pieces of the system can you remove before it stops working/has a major effect?

At the conclusion of the afternoon breakout session, the group reviewed the questions and responses captured during the day. The group was asked to select three to five key takeaways from the session. The general consensus of the group is summarized in Table 23.

Table 23. Key Takeaways from the Transportation Sector Breakout Session

\section{Transportation Breakout Session Key Takeaways}

- $\quad$ Separating the built environment specific to transportation from the aspect of the social elements of disaster resilience, (in particular, evacuation, health and human safety, and human behavior prediction), is difficult. In writing the report, NIST should consider the extremely close relationship between the resiliency of a transportation network and its ability to usher and sustain human activity pre, during, and post disaster.

- The interdependency of the built transportation environment with other sectors, namely energy, water, and communication and information sectors, is a key component of community disaster resilience as highlighted by the example of the NJ Transit system during Hurricane Sandy, (where the subway and flood pumps couldn't work due to flooded switches and pumps and lack of electricity). The report should take into considerations these deeply embedded sector dependencies.

- $\quad$ Consider developing metrics for the transportation sector that consider transportation systems as a service. Evaluation of a community's disaster resilience can be defined by how well this service is responding to the needs of the community in pre, during, and post disaster situations in routine, expected, and extreme events. 


\section{Breakout Session \#4: Framework Chapter 7 - Power/Energy Sector}

The Power/Energy Breakout Sessions were attended by practitioners, policy/regulatory stakeholders, researchers, non-profit organizations, and government employees. The breakout groups started with an introduction of each of the participants. During the introductions, a participant stated that the Department of Energy (DoE) has an initiative called the Energy Assurance Program of Insurance. As part of the initiative, they are developing guidance on energy sector resilience and suggested that the team developing the framework should look into this effort as a potential good source of information.

Once the introductions of the participants were completed, the morning breakout session began with the facilitator asking a typical brainstorming question to engage to the participants:

"What are key elements and characteristics in a disaster resilience framework to guide community planning in the power/energy sector?"

This question was asked independent of what was in the $25 \%$ draft of the framework provided to participants in advance of the workshop, in part, so that the writing team could contrast and compare what the stakeholders wanted to see in the framework with what was in the $25 \%$ draft.

The breakout group expressed a need to identify critical infrastructure, its capabilities, limits and how long they can or cannot provide power in a disaster event. The group also discussed interdependencies and consistency with other sectors as well as within the energy/power industry, as can be seen in Table 24. Naturally, the participants agreed that communication between and within sectors needed to be improved to make sure that everyone was on the same page. The thought was that cross-sector coordination and communication would result in consistent policies, codes and standards, and harmonized safety related actions.

Participants pointed out that the power/energy sector is not just one system and that the different components, (e.g., generation, transmission, distribution, etc.), need to be addressed in the framework. The need for common, comparable simple methods for analyzing risk and dependencies for all infrastructures should be developed. 


\section{Table 24. Key Element and Characteristic for Disaster Resilience Framework in the Power/Energy Sector}

\section{Q1: What are key elements and characteristics in a disaster resilience framework to guide community planning in the power/energy sector?}

- Common/comparable simple methods to analyze all individual lifeline system's risks and the interdependencies among them

- Ways to analyze risk and expected outage valued from perspectives of system owner and the public to get to externalities

- Understanding how the different electric components work and who is responsible for what function. This would include the points of service.

- Harmonization of safety-related actions

- Back-feed, voltage, personnel

- Central communications

- Consistency of policy and standards

- Outline of an energy assurance plan that can be adopted for use

- Same background to guide development

- Interagency planning and communications. How does civilian infrastructure provide tie-in to the process? Power vs. possible roadways.

- A balance between resilience for natural and man-caused hazards (e.g., cyber threats). Also, integrating with other sectors to have robust short- and long-term recovery strategies.

- Explore opportunities for experience-based learning for operators

- Explain to emergency managers and community planners what you are asking them to actually do

- Provide real examples and resources pages - to contacts other agencies, etc.

- Current vulnerabilities in "last mile," substations, regional grid - Are there redundancies in these areas?

- Response process

- Coordination with electric, fuel water/healthcare/food

- Identification of critical infrastructure in and around community and their capabilities to handle no power

- Codes and standards

- Clear performance objectives

- Guidance on expectation management

- The availability of Distributed Energy Resources (DER) in the local disaster area. Are they mobile? If fixed, is the facility with DER a shelter? Can the DER be operated in island mode, isolated from the grid with black start capabilities?

The second question asked of the participants was:

"Who should define the performance goals and make the decisions for a community or regional disaster resilience plan in the power/energy system sector?"

The participants did not have a lengthy discussion with respect to who should be responsible for defining the performance goals, as can be seen from the points presented in Table 25. However, it was agreed that there should be collaboration between regulators, private sector representatives, the utility commission, power producers/generators, and other representatives from other sectors who depend on power, (e.g., buildings, water, and communications sectors). Participants discussed the fact that utilities cannot harden their systems without getting approval for a rate increase (as a result of hardening) from the Public Utilities or Service Commission (PUC or PSC). 
There was some discussion within the group with regards to whether the power/energy industry was regulated on not. It was noted that the practitioners did not feel there was regulation within the industry, but regulatory participants stated that if there is a standard that is in a state or federal statute, the industry must adhere to it.

The participants encouraged the writing team to be aware of other efforts when developing a national resilience framework and stated that there are a lot of recovery plans being written by different groups. It was stated, again, that there was a need for coordination between these groups, which includes power producers, hazard mitigation groups, private sector, other sectors, (who all rely on power), and elected officials who approve plans.

\section{Table 25. Parties Responsible for Defining Performance Goals in Power/Energy Sector}

\section{Q2: Who should define the performance goals and make the decisions for a community or regional disaster resilience plan in the power/energy systems sector?}

- Should be a collaboration between regulators, private sector, utility commission, power producers, and even other dependent sectors

- Public Service Commission (PSC)

- Mayor-city council, the President, Congress - It should be at the chief executive level and flow down to the regional level

- If all-hazard risk and outage are evaluated from specific perspectives of owner and public, expect owner to make investments with minimum returns on investment. Unfunded investment opportunities with large public benefits are argued to PUC and local/state (executive) governments

Once the group finished their discussion of who should define the performance goals and decided that it needed to be a collaborative effort with the various stakeholders, the group was asked to take the next step and list the levels or sublevels for which performance goals should be defined. This question resulted in an interesting discussion with varying perspectives. As can be seen in Table 26, the participants felt that the levels/sublevels at which performance goals should be defined were consistent across the various hazard levels, (routine, expected, extreme).

For electricity, the group agreed fairly quickly that the goals should be to define performance goals at the sub-sub level for distribution, (i.e., a lot of granularity). The idea for distribution was to start at the end-user and work back towards the supply. The participants stated that the Federal Energy Regulatory Commission (FERC) should regulate wholesale of energy. There was also some discussion that substations should be considered for transmission, but was not fully agreed upon. 
Table 26. Levels of Assigning Performance Goals for Disaster Resilience in the Power/Energy Sector

\begin{tabular}{|c|c|c|c|}
\hline & Routine & Expected & Extreme \\
\hline \multicolumn{4}{|l|}{ Electricity Subsector } \\
\hline - Generation & - FERC/PSC & - FERC/PSC & - FERC/PSC \\
\hline - Transmission & - FERC/PSC & - FERC/PSC & - FERC/PSC \\
\hline $\begin{array}{l}\text { - Distribution (sub-sub levels): } \\
\text { - Fuel } \\
\text { - Water } \\
\text { - Transportation } \\
\text { - Telecom } \\
\text { - Health care } \\
\text { - Food }\end{array}$ & - At sub-sub-level & - At sub-sub-level & - At sub-sub-level \\
\hline \multicolumn{4}{|l|}{ Natural Gas Subsector } \\
\hline $\begin{array}{l}\text { - Transmission } \\
\text { - Old cast iron pipes } \\
\text { - New pipes }\end{array}$ & - At transmission level & - At transmission level & - At transmission level \\
\hline \multicolumn{4}{|l|}{ - Gas Stations } \\
\hline - Distribution & $\begin{array}{l}\text { - At end-use levels } \\
\text { (residential, } \\
\text { commercial, } \\
\text { industrial, etc.), } \\
\text { based on their needs }\end{array}$ & $\begin{array}{l}\text { - At end-use levels } \\
\text { (residential, } \\
\text { commercial, industrial, } \\
\text { etc.), based on their } \\
\text { needs }\end{array}$ & $\begin{array}{l}\text { - At end-use levels } \\
\text { (residential, } \\
\text { commercial, industrial, } \\
\text { etc.), based on their } \\
\text { needs }\end{array}$ \\
\hline \multicolumn{4}{|l|}{ Liquid Fuel Subsector } \\
\hline \multicolumn{4}{|l|}{ - Refining } \\
\hline \multicolumn{4}{|l|}{ - Transmission } \\
\hline \multicolumn{4}{|l|}{ - Storage } \\
\hline - Distribution & $\begin{array}{l}\text { - Performance goals } \\
\text { set by type of fuel } \\
\text { use }\end{array}$ & $\begin{array}{l}\text { - Performance goals set } \\
\text { by type of fuel use }\end{array}$ & $\begin{array}{l}\text { - Performance goals set } \\
\text { by type of fuel use }\end{array}$ \\
\hline
\end{tabular}

For the natural gas subsector, the participants felt that separate performance goals should be set for old and new pipes of the transmission system. The participants agreed, as was done for electricity, that performance goals for the distribution system should be defined at the end-user level, (i.e., sub-sub level). It was noted that regulations for distribution takes place at the federal and state levels, with the exception of distribution to buildings, which should be regulated by local codes. Some participants also cautioned defining performance goals at different levels because it may lead to unfair competition between energy types, which communities typically want to avoid.

For the liquid fuels, the group felt that there was no reason to have a different structure, (in terms of levels), for defining performance goals. It was noted that the state of New York has requirements to provide standby generators at specific gas stations. 
As previously discussed, the morning breakout session focused on what the participants/stakeholders would like to see in the framework. In the afternoon, the focus switched to challenges and implementation of the framework. The first question asked of the participants in the afternoon, (the fourth question overall), was:

"Assume that your desired end-state is a well-defined disaster resilience plan with set targets for the built environment. What are the main barriers and challenges to creating and executing the disaster resilience framework for the power/energy sector?"

As can be seen in Table 27, the barriers were generally broken down into five categories of barriers: responsibilities, regulation, perception, funding, and other. The participants expressed some concern that the NIST effort is one of many frameworks, and it will need to differentiate itself from others to be accepted and practically applied. However, it was noted that the NIST effort is working with other parts of the federal government to coordinate efforts and frameworks to limit the amount of overlap. This framework encompasses the built environment as a whole rather than specific components as was discussed during the opening session of the workshop.

Table 27. Barriers and Challenges to Executing Implementation of the Disaster Resilience Framework in the Power/Energy Sector

\section{Q4: What are the main barriers and challenges to creating and executing the disaster resilience framework?}

\begin{tabular}{|c|c|c|}
\hline Responsibilities & Regulation & Perception \\
\hline $\begin{array}{l}\text { - Communicating roles and } \\
\text { responsibilities } \\
\text { - Training to assure tasks are } \\
\text { known } \\
\text { - Division of responsibilities } \\
\text { during the event } \\
\text { - Lack of agreement } \\
\text { - Priorities } \\
\text { - Methods } \\
\text { - Communication of goals/needs } \\
\text { - Finding qualified } \\
\text { - } \text { assets/personnel } \\
\text { in-charge } \\
\text { - Build ownership/trust }\end{array}$ & $\begin{array}{l}\text { - Duplication of efforts by } \\
\text { other } \\
\text { agencies/organizations } \\
\text { - "How does this apply to } \\
\text { me?" attitude } \\
\text { - Who were the stakeholders } \\
\text { that were involved? } \\
\text { - Unfunded mandate } \\
\text { - Political buy-in and funding } \\
\text { - Agreement across "political" } \\
\text { - Coundaries" }\end{array}$ & $\begin{array}{l}\text { - How do I implement it on the ground level? } \\
\text { - Where do these concepts come from and } \\
\text { are they required? } \\
\text { - No perceived value of the framework } \\
\text { - Now (short-term) } \\
\text { - Later (long-term) } \\
\text { - There are many different frameworks out } \\
\text { there. Why is this one different? Why this } \\
\text { framework versus another? } \\
\text { - Community and private sector buy-in } \\
\text { Buy-in from all separate resiliency } \\
\text { frameworks (IPP, NRF, pre-disaster } \\
\text { mitigation plans, etc.) }\end{array}$ \\
\hline Funding & \multicolumn{2}{|l|}{ Other } \\
\hline $\begin{array}{l}\text { - Funding - understanding what } \\
\text { is expected by the different } \\
\text { owners for the total services, } \\
\text { maintaining competitiveness - } \\
\text { everyone gets to the same level } \\
\text { - Funding for private sector } \\
\text { improvements }\end{array}$ & \multicolumn{2}{|c|}{$\begin{array}{l}\text { - Code issues } \\
\text { - Uninterruptable supply of fuel } \\
\text { - Utility franchise rights limit micro-grids as a resiliency measure } \\
\text { - Lack of drills and practices } \\
\text { - Even table top exercises would be very helpful } \\
\text { Sensitivity of information prevent information dissemination }\end{array}$} \\
\hline
\end{tabular}


The participants also stated that a conflicting regulatory environment may lead to difficulties in implementation of resilience focused efforts. Others pointed out the some stakeholders who were not involved in the framework development process may be hesitant to use something for which their input was not included. As expected, funding and cost were core issues for implementing the framework.

The group also stated that developing the document was a good and necessary idea. However, they felt that roles and responsibilities need to be communicated for execution. Participants also provided helpful ideas/suggestions such as developing an implementation plan and working groups with expert focus as the NIST Smart Grid effort has done, and making sure the right representatives get involved in the process.

Once the barriers/challenges were discussed, the next question asked was to determine what is needed to support disaster resilience:

"What new/updated/improved standards, codes, models, practices, and thresholds/performance goals are needed in the power/energy sector?"

The participants' discussion and thoughts were broken down into four categories, as shown in Table 28. The categories were: codes, metrics, models, and other. When discussing codes and standards, the participants felt there was need for the codes and standards to include a clear definition of expected system performance goals rather than for safety as is the current purpose. Furthermore, the concern is commonly that codes will conflict, and thus, code harmonization was identified as a key need. The need for a loading standard was also discussed and it was noted that National Electrical Safety Code (NESC) is currently working on the development of one.

With regards to metrics, the participants expressed the desire for criteria to evaluate the robustness of equipment and facilities. It was noted that current standards do touch on these, but there needs to be more focus in this area. The group also was interested in more models being developed, especially those that include the entire system and can demonstrate the impact of cascading effects.

The participants discussed the issue, (which they felt was typically unspoken), that the current business model of being paid by the kilowatt hour will make it difficult for resilience strategies to be implemented, and thus identified it as another barrier to achieving resilience.

In addition to updates in codes, standards, metrics, and models, the group felt there were other things that could be done to help enhance the resilience of power/energy system. For example, it was felt that pre-disaster drills and exercises could be conducted to aid in short-term recovery. 
Table 28. Improvements to Current Standards, Codes, Models, and Practices Needed to Support Disaster Resilience in the Power/Energy Sector

\section{Q5: What new/updated/improved standards, codes, models, practices, and thresholds/ performance goals are needed?}

\begin{tabular}{|c|c|c|c|}
\hline Codes & Metrics & Models & Other \\
\hline $\begin{array}{l}\text { - Define expected system } \\
\text { performance goals, } \\
\text { current design and safety; } \\
\text { not community } \\
\text { performance } \\
\text { - Performance--oriented } \\
\text { standards and codes } \\
\text { - Do not attempt to } \\
\text { specify/regulate } \\
\text { technologies } \\
\text { - Ensure no duplication of } \\
\text { codes } \\
\text { - Process to harmonize } \\
\text { conflicting codes } \\
\text { - Need a design } \\
\text { code/standard for } \\
\text { function areas }\end{array}$ & $\begin{array}{l}\text { Facility and equipment } \\
\text { robustness } \\
\text { criteria/metrics. Existing } \\
\text { standards touch on } \\
\text { these, but do not focus } \\
\text { on these metrics. }\end{array}$ & $\begin{array}{l}\text { - Need models and } \\
\text { standards information } \\
\text { sharing across various } \\
\text { systems } \\
\text { - Modeling has } \\
\text { attempted to build } \\
\text { interoperability } \\
\text { between energy and } \\
\text { other sectors within } \\
\text { community - not sure } \\
\text { they have this solved } \\
\text { without parameters } \\
\text { - System-wide models } \\
\text { - Cascading effects } \\
\text { - Unintended } \\
\text { consequences } \\
\text { - If DER (for Distributed } \\
\text { Energy) } \\
\text { - New utility } \\
\text { fund/financing } \\
\text { model (rate } \\
\text { structure) to move } \\
\text { power locally not } \\
\text { wholesale }\end{array}$ & $\begin{array}{l}\text { - Support to upgrade } \\
\text { and secure } \\
\text { transmission systems- } \\
\text { both liquid and electric. } \\
\text { - Ease of barriers to } \\
\text { do the above } \\
\text { - Regulator } \\
\text { discussions } \\
\text { - Do not exchange } \\
\text { cards at the scene } \\
\text { - Allow self-identification } \\
\text { of faults } \\
\text { - Pre-disaster drills and } \\
\text { exercises } \\
\text { - Re-energization of } \\
\text { standards common to } \\
\text { all } \\
\text { - Asset harmonization } \\
\text { (like units) } \\
\text { - Performance-based } \\
\text { design } \\
\text { - Progressive collapse } \\
\text { (best practice) } \\
\text { - Do not allow waivers to } \\
\text { codes and standards } \\
\text { due to financial } \\
\text { constraints, it has long- } \\
\text { term impacts } \\
\text { - Assess benefit/cost to } \\
\text { new standards }\end{array}$ \\
\hline
\end{tabular}

The group was then asked:

"What are the knowledge needs or gaps in your community relative to disaster resilience in the power/energy sector?"

As shown in Table 29, the responses where categorized into Dependencies, Inventories, and Other. The group felt that communities needed to better understand interdependencies, (either within the sector or with other sectors), which we often learn when a component fails and shuts down all or part of the system. The modeling of interdependencies with other sectors, specifically the water and transportation sectors, is something that is needed to ensure the water and transportation sectors are not significantly impacted in the event of a disaster. The group also discussed the need to understand the economics of the sector because it is largely held by private entities, which are highly driven by money. Other useful suggestions were made, including 
creating an inventory or inventories of critical assets and equipment, as well as orchestrating an annual convention to bring stakeholders to together.

Table 29. Knowledge Needs and Gaps in Disaster Resilience for Power/Energy Sector

\begin{tabular}{|c|c|c|}
\hline \multicolumn{3}{|c|}{$\begin{array}{l}\text { Q6: Knowledge needs in your } \\
\text { community relative to disaster resilience in this sector }\end{array}$} \\
\hline Dependencies & Inventories & Other \\
\hline $\begin{array}{l}\text { - Interdependence analysis and } \\
\text { modeling } \\
\text { - System dependencies (internal } \\
\text { and external to power systems) } \\
\text { - Interconnections with other parts of } \\
\text { critical infrastructure (reference } \\
\text { architecture?) } \\
\text { - Need to understand the economics } \\
\text { of interdependencies } \\
\text { - Interdependences: need to define } \\
\text { how to improve an electric power } \\
\text { system to meet the expected } \\
\text { performance goods }\end{array}$ & $\begin{array}{l}\text { - National inventory of available } \\
\text { assets, equipment, people, } \\
\text { resources, etc. } \\
\text { - Annual best practices workshop } \\
\text { to share ideas } \\
\text { - Inventory of critical assets } \\
\text { (ongoing) } \\
\text { - Past performance under duress } \\
\text { - Lessons learned } \\
\text { - Access to this information }\end{array}$ & $\begin{array}{l}\text { - Understanding the congestion } \\
\text { issues on the distribution to focus } \\
\text { resiliency DER } \\
\text { - Do not believe "we" understand the } \\
\text { options for solutions } \\
\text { - Energy } \rightarrow \text { Water/fuel/telecom } \\
\text { (etc.) } \\
\text { - Energy } \rightarrow \text { Distribution } \\
\text { - Energy } \rightarrow \text { Government }\end{array}$ \\
\hline
\end{tabular}

The final question asked of the participants in the breakout group was:

"What evaluation methods, specific to the power/energy sector, are needed to determine the effectiveness in community disaster resilience?"

Table 30 illustrated that the ideas provided by the participants were divided into 3 categories: Monetizing, Standardization, and Other. The participants discussed the need to be able to evaluate their return on investment for upgrades made. As was discussed in response to previous questions, the energy sector is largely held by private entities and, therefore, need tools to ensure that their investments are worthwhile and the cost/benefit ratios can be determined. The group also expressed the desire to establish a standardized vulnerability assessment tool to help evaluate how resilient systems are or have become. Similarly to other sectors, the need for scientific models to quantify resilience by providing metrics and solutions was identified by participants. 
Table 30. Evaluation Methods Needed Specific to the Power/Energy Sector

\section{Q7: Evaluation methods specific to this sector needed to determine effectiveness in community disaster resilience}

\begin{tabular}{|c|c|c|}
\hline Monetizing & Standardization & Other \\
\hline $\begin{array}{l}\text { - Tracking of losses/impacts } \\
\text { avoided } \\
\text { - Trend analysis for average } \\
\text { annual loss/economic impact } \\
\text { - A cost/benefit model that } \\
\text { includes the cost and benefits of } \\
\text { lost loads }\end{array}$ & $\begin{array}{l}\text { - Standardized vulnerability } \\
\text { assessment tools! How do I know I } \\
\text { made it to the performance goal? } \\
\text { - Define the needs (standard?) } \\
\text { - Execute a model reflective of the } \\
\text { needs } \\
\text { - Test, retest } \\
\text { - Standard risk assessment } \\
\text { methodologies }\end{array}$ & $\begin{array}{l}\text { - Planned vs. actual restoration } \\
\text { time data } \\
\text { - Timelines on events/cascading } \\
\text { faults } \\
\text { - Post-mortem reports on what } \\
\text { worked or did not relative to plans } \\
\text { (without repercussions) } \\
\text { - Is it possible to compare } \\
\text { localities/cities abilities to } \\
\text { withstand incidents? } \\
\text { - Is it possible to score resiliency? }\end{array}$ \\
\hline
\end{tabular}

At the conclusion of the afternoon breakout session, the group reviewed the questions and responses captured during the day. The group was asked to select three to five key takeaways from the session. The general consensus of the group is summarized in Table 31 .

Table 31. Key Takeaways from the Power/Energy Sector Breakout Session

\section{Power/Energy Breakout Session Key Takeaways}

- Performance goals need to be established at the sub levels, (e.g., generation, transmission, distribution), and sub-sub levels, (e.g., elements of transmission).

- This is just another framework if it is not required - why do I do this and lose my market advantage?

- Need more representatives at the workshops to show and provide buy-in to the framework for it to be successful. This is a complicated sector.

- The current business model of getting paid on the kWh is a barrier to innovation and investing in resilience.

- $\quad$ Need an information sharing network that is secure and will not penalize a utility or entity when they have a problem and seek help. 


\section{Breakout Session \#5: Framework Chapter 8 - Communication and Information Systems Sector}

At the beginning of the session, introductions were made and Dr. Vickery, the attending Chapter author, discussed his background and the contents of the Chapter. Dr. Vickery asked how many of the session participants had read the $25 \%$ draft version of the Chapter and only a handful of the participants had read the document.

The communication and information systems breakout session was designed so the participants would answer seven key questions. There was a tendency for the group to focus on emergency response, (and in some cases, preparedness), rather than focusing on the longer term goal of building a resilient communication infrastructure. Attempts were made to refocus the group on the longer term issues associated with building disaster resistant infrastructure, but invariably they would refocus on disaster response.

Participants were to respond to each question by writing their answers or comments on one or two cards. The cards were then posted at the front of the room and a discussion of the notes ensued.

The first question posed to the session participants was:

"What key elements and characteristics would you find to be the most useful in a Disaster Resilience Framework that is intended to guide community planning for Communication and Information System (CIS) disaster resilience?"

The responses given on the cards are summarized in Table 32.

The service provider participants felt it was important that the resilience framework contain information on successful configurations associated with good performance during past events. They felt it would be useful if there were guidelines for measuring performance after events so there was quantitative information comparing the performance of various systems, (e.g., above ground vs. below ground communication infrastructure). The resilience framework should address best practices currently used by the service providers. The providers felt it was important that the user community, (homeowners, businesses, etc.), be educated so they know what to do to ensure their equipment functions after the loss of power that usually occurs following a natural disaster. The guidance should reflect the hazard to which the users are exposed, (e.g., flood prone area vs. not likely to flood). The resilience framework should present guidelines as to how long it should take to restore communications and information services, as well as prioritization of the order in which services should be restored. 


\section{Table 32. Key Elements and Characteristics of Communication and Information System Sector for Disaster Resilience Framework}

\section{Q1: What key elements and characteristics would you find to be the most useful in a Disaster Resilience Framework that is intended to guide community planning for Communication and Information System (CIS) disaster resilience?}

- The Framework should reflect:

- "Success configuration(s)" - the matrix of conditions and capabilities (both internal and external to the sector) for CIS functionality

- The marginal cost of achieving increased levels of performance

- Funding constraints and the challenge of charging customers for resilience measures in a highly price sensitive and price transparent market

- The diversity of CIS configurations

- Performance factors during various disaster scenarios

- The time sensitivity of CIS content -i.e., given the rapid rate of change in CIS technologies, the Framework and resulting plans will have to be flexible/adaptive with regard to CIS

- Role of information systems in improving public situation awareness

- Lessons-learned from the Nuclear Power Initiative to improve sector resilience

- The Framework should include:

- Best practices -including those for the role of the end-user (such as use of changers, generators, batteries, etc.)

- Potential sources of funding, including the role (or potential role) of public service commissions in approving service surcharges to pay for resilience costs over the long term (similar to E911 or LNP surcharges)

- Guidance on the development of system restoration priorities and time-to-recovery targets

- Support for information-sharing resilience, i.e., redundancy of information pathways ("adaptive information sharing"), such as support for ongoing ham radio use so expertise and resources are ready when needed for communications redundancy during the early stages of a disaster

- Information resources (web sites/phone numbers/documents)

- Standards of performance (such as ASW vs. BSW cable during disasters)

- Catalogue of existing best practices and standards that may be relevant to CIS resilience

- Guidance/information/resources to help stakeholders determine the CIS configurations most important for resilience

- Role of CIS in pre-disaster citizen engagement that may help to improve community resilience

- Ways in which CIS providers can provide consumers with resilience options and tools (such as providing solar rechargers as a purchase or bonus options)

- Planning-based or subscription-based community/personalized notification

- Built infrastructure status

The second question focused on who should be responsible for setting the performance goals. Here again, the conversation focused on the performance requirements immediately following a disaster. This focus is reflected in the first three entries in Table 33 which summarizes the participants' responses given in the form of cards. The group felt it was important that first responders and emergency management folks play a role in setting performance goals. The service providers felt that representation from the service providers in setting performance goals was also needed. The framework should recognize funding constraints as the industry is highly competitive. The industry was opposed to "regulating" resilience.

There was a discussion that the service carrier that builds the most resilient network would win more customers, (i.e., self-imposed improved resilience). This discussion focused on the thought that the service provider that performed best, (i.e., those with a more resilient network), during and after an event was likely to add to its subscriber base, (i.e., picking up subscribers from 
networks that did not perform well). However, the service providers were quick to point out that service providers often share infrastructure. For example, AT\&T might lease Verizon backhaul capacity or vice-versa, so the failure of the Verizon portion of the backhaul would impact AT\&T's services.

Table 33. Parties Responsible for Defining Performance Goals for Community and Regional Disaster Resilience Plan in Communication and Information Sector

\section{Q2: Who should define the performance goals and make the decisions for a community or regional disaster resilience plan}

- First responders

- Service providers

- Emergency management personnel

- Consumers/end users (who ultimately must fund resilience investments)

- CSRIC

- Public service commissions

- Organizations/agencies which account for vulnerable populations - disabled/non-tech conversant and tech adverse)

- Community organizers/organizations

- Local government (city, county, state)

- Alliance for Telecommunication Industry Solutions (ATIS) (www.atis.org) "NRSC" committee (which addresses technical and operational guidance for network reliability)

- Stakeholder SMEs, particularly in the development or implementation of resilience goals, codes, or standards

- Social network hubs
- School principals

- Faith based organizations

- Local responders

- Social networking experts/researchers

- Business/business organizations

- Federal agencies, including FCC, FEMA (including FEMA/CERT coordination teams), National Guard, USACE, including USACE /EPFAT (the office that has the generator database)

- NGO's (VOADs), Red Cross, food banks

- First Net

- Broadcasters PIO

- Carnegie Mellon University /Software Engineering Institute, WEA

- Faith-based organizations (FEMA coordination)

- State fusion centers (data-sharing law/inf Task Forces [?]

- National guard industry [?]

The third question focused on developing a resilience matrix for communications and information systems (CIS) examining components and sub-components. The question was posed as:

"Please review the Disaster Resilience Matrix, cluster definitions, and hazard and event levels in your handout. What are the facilities and infrastructure that we need to include in Critical Response Buildings, Emergency Housing, and Support Systems? Same for the other clusters? From a disaster resilience perspective, does it work to deal with these clusters at the levels they are defined, and at these hazard levels, (3 levels of hazards)?That is, do you need more levels?"

The groups' responses as given on the cards are summarized in Table 34.

The discussion started with the facilitator developing a list of components associated with the Cyber Infrastructure (CIS) components including wire-line, (co-axial cable, fiber-optics, and copper), wireless, (including cellular telephone and data, wi-fi, and micro-wave), data centers, and satellite. Buildings and towers and other physical infrastructure were not included in the list. The providers steered the component list away from wire-line, wireless, etc., and focused on 
services and the importance of services. The list included television, (noted to be the least important), text, voice, and Internet. It was suggested that the performance goals should be determined by service without recognition of the method of providing the service. Here, it was recognized that to achieve a given performance in terms of service, we must look at the performance of the physical infrastructure, such as the backhaul network. It was noted that in establishing performance goals, realistic goals must consider the order of restoration. For example, the lack of power is often the reason for failure of portions of the communication network. Furthermore, the restoration of service provided by above ground wires cannot begin until the electric utility has restored the above ground lines, (in most cases telecommunication providers lease access to the electric utilities poles).

\section{Table 34. Components and Subcomponents of CIS Infrastructure}

\section{Q3: Developing a Simplified Disaster Resilience Matrix for CIS infrastructure - Components and Sub-Components}

\section{3a. What are the facilities and infrastructure that we need to include in a CIS resilience matrix?}

- CIS configurations generally, and those most important for community resilience, are highly variable from region to region. A resilience Framework and matrix for CIS must therefore recognize the universe of CIS capabilities and services that likely are employed in CIS lifeline configurations. The resilience of these lifeline CIS capability and service configurations may then be assessed/improved based on the specific technologies regionally employed. Relevant CIS lifeline services include:

- Two-way communications, particularly mobile voice and data (text)

- Mass notification

- Transaction communications (credit/ATM) and related business services

- 911 services

- Emergency response and emergency management communications

- News and situation-awareness information sharing

- The CIS configurations necessary to support these services are comprised of similar, but not identical, infrastructure/clusters depending on service population, geography, provider, and other variables. Relevant $\mathrm{CIS}$ infrastructure/clusters include:

- GIS

- Data storage

- Radio LMR

- Wireless ad hoc (hotspots)

- Wi-Fi (including a hardened Wi-Fi network for voice and text resilience)

- Cellular communications infrastructure

- Satellite systems

- Network sensors

- Data storage

- Hosting

$3 b / 3 c$. From a disaster resilience perspective, does it work to deal with these clusters at the levels they are defined, i.e., do you need more levels? From a disaster resilience perspective, does it work to deal with these clusters at the hazard levels in the example matrix or are more hazard levels necessary?

- While sub-level descriptions are generally possible for these technologies, the regional variations in both the lifeline CIS service configurations and the CIS technologies which support those services makes sublevels highly problematic or impossible for performance target setting regardless of the number of hazard levels included. 
The group felt that the community needs to identify the communication needs of the Emergency Operations Centers (EOC's), police, etc., in order to prioritize infrastructure improvements to improve resilience.

While the order of restoration of services is dictated by the FCC, the group suggested that the order of restoration should ensure that the 9-1-1 service, (both reverse and push), be the first priority, with the second priority being the restoration of the wireless network, (voice and text), followed by broadband, (data), and then broadband for television. Restoring data transmission at locations of ATM's was felt to be important so that folks could get the cash they need to buy food, etc.

The responses to the fourth through seventh questions are summarized in Table 35.

The fourth question posed was:

"Assume that your desired end-state is a well-defined disaster resilience plan with set targets for the built environment. What do you think will be the primary barriers, challenges, or impediments to creating and executing your disaster resilience plan, from a community, personal experience, regional, or national perspective?"

Some of the key barriers and challenges to building a resilient communications infrastructure include:

- Determining the ownership of various portions of the infrastructure. Examples include Central Offices located in leased buildings; cellular tower space is often leased from a third party. In highly urbanized areas, cell towers are often located on the top of buildings owned by third parties.

- Within sector interdependencies, include such things as one carrier leasing capacity or infrastructure from another carrier.

- Cost is a big issue as the rates that the various service providers can charge is very competitive so margins are low.

- Too many goals competing for limited funding. To alleviate this problem, it was recommended that communities focus on achieving one goal at a time.

- There was concern that there may be multiple programs to improve resiliency with each having different or competing objectives.

- Legal challenges, (associated with privacy, for example), may preclude offsite back-up of important data.

The fifth question posed was:

"What new/updated/improved standards, codes, models, practices, and thresholds/performance goals are needed to support effective disaster resilience in this sector?" 
The group shied away from addressing codes, but focused on communications associated with warnings ensuring all communications were readily understood by layman and addressing issues associated with communications to the non-English speaking communities.

Sharing of best practices and lessons learned should be encouraged and made available to all within the community, (e.g., Ready New York). This information would be used to help the community prepare for disasters.

There needs to be adequate training once the resilience framework is implemented and the framework needs to be updated once written. Communities need to use existing sensor technologies to assess existing vulnerabilities by tracking traffic patterns, etc., and using this information to predict and understand the behavior of the community.

The sixth question posed was:

"What general additional knowledge requirements, (data and models), will help communities respond to disasters more effectively?"

There needs to be a way for the costs and benefits associated with building a more resilient communications network to be quantified and to demonstrate the business case to the community. The communities need to understand the complexities, the interdependencies between service providers, and the interdependencies between the communications sector and other lifeline sectors.

Tools should be available for communities to model scenarios to determine the vulnerabilities and the impact of these vulnerabilities on ability to provide services. Such a tool currently does not exist. Tools should be developed to provide updates to the community on the post event restoration progress.

The seventh and final question posed was:

\section{"What new evaluation methods should be developed?"}

By the time the group attempted to answer this question, time was very limited. The key suggestions included the ability for communities to measure resilience associated with redundancies and the ability to understand the interdependencies, particularly the dependence on the need for power. It is important for information on lessons learned during past events to be captured and disseminated. 
Table 35. Barriers/Challenges for Framework Implementation and Needs to Overcome Challenges

\section{Session II: Barriers/Challenges; Standards, Guides; Measures; Knowledge Needs}

- Interdependencies - both within CIS and among other infrastructure sectors/clusters

- Electricity enables nearly all CIS configurations

- CIS lifeline system and variation

- Identifying ownership/responsibility

- Conflicting priorities among stakeholder groups

- Too many goals competing for limited resources - leads to unfunded and uncoordinated projects and minimal progress

- Legal constraints on copying/duplicating data for backup (e.g., medical)

- Dynamic data collection for situation awareness (different data at different times)

- Scale of information streaming from sensors (sometimes small, sometimes huge)

- Multi-vendor environment

- Multi-provider environment

- Economic model of CIS - need for modeling once Framework is established

- Economic impact to non-rate of return companies - Funding

- Overlap with existing plans

- Policy (consistency) federal/state/agencies

- Conflicting needs for different communities

- Conflicting and uncoordinated disaster plans and frameworks

- Aesthetics/planning

- Must empower citizens/communities, reducing excessive reliance on uniformed responders

- Adequate training/practicing once implemented

- Adequately updating once written
New/Updated: Standards, Codes, Guidance, Practices

- Standards for information dissemination to public, e.g., in own language - provide "take action" SEI/CMSU's (see SEA

- End user best practices/guidance

- Identifying priorities (Golden Tree concept)

- Communications:

- Provisions to meet all members of communities' abilities: non-English speakers, hearing impaired, blind, etc.

- "Plain English" standards (i.e., all communications (pre, during, and post event) are clear, precise, meaningful to general population (e.g., NOAA predicted Irene very accurately but announced the extreme precipitation expected in too technical a manner)

- Cross Sector collaboration methods and practices

- Con Ed is rolling out a new technology-based method to troubleshoot power outages. Is this adaptable for other sectors?

- Standardization of metrics

- A community resilience toolkit to support best practices with regard to telecom and information access

- Information-sharing standards

\section{Knowledge Needs} (Data, Models)

- Resilience costs and benefits money - business case development for appropriate audiences

- Communities need to know their specific technology/service dependencies

- Independencies modeling generally, including interdependencies among CIS elements and functions, as well as interdependencies between CIS and other lifeline systems

- Ways to utilize the information provided by the sensors now prevalent

- Models/methods for comprehensive mapping of local/regional vulnerabilities including the nature/impact of the vulnerability including the its nature/impact

- Codes/standards framework

- Intelligent/adaptive" checklist that varies according to the key risks that a community faces Systems to provide updates to the community given various outage situations

\section{New Evaluation Methods}

- Measure redundancies

- Measure interdependencies Lessons-learned capture and dissemination before community goes "back" to new normal 
At the conclusion of the afternoon breakout session, the group reviewed the questions and responses captured during the day. The group was asked to select three to five key takeaways from the session. The general consensus of the group is summarized in Table 36.

Table 36. Key Takeaways from the Communication and Information Systems Breakout Session

\section{Communication and Information Systems Breakout Session Key Takeaways}

- $\quad$ Face-to-face stakeholder collaboration in framework development is important to foster trust and understand the complexity of diverse stakeholder roles and responsibilities.

- Importance of focusing on services over specific technologies in developing a more meaningful and useful framework. There are many variations in topography and technology types depending on factors such as population, topography, vendors, etc.

- $\quad$ The Framework will need to account for the price competitive and price transparent CIS market. Developing a business case investment is challenging but imperative. 


\section{Breakout Session \#6: Framework Chapter 9 - Water and Wastewater Sector}

The Energetics Incorporated facilitator for the water and wastewater breakout session, welcomed everyone, explained the intent of this workshop, (i.e., to provide the lead chapter author with input that will help NIST to develop a Disaster Resilience Framework that will help guide communities in disaster planning), went over the breakout session components, and reviewed the overall process and ground rules of the breakout session.

The facilitator then introduced Dr. Kent Yu as the leading chapter author for the water and wastewater systems, and led the introduction of every participant around the room, including their name, affiliation, and area of interest in disaster resilience.

Dr. Yu provided a five-minute overview of the chapter, and indicated that the chapter was built upon his previous work on The Oregon Resilience Plan, and thus was heavy on earthquake and tsunami hazards. Ms. Adrienne Sheldon would expand the chapter to cover wind and flood as additional hazards. He started with a brief discussion of the overall chapter structure, including:

- A description of the complex nature of water and wastewater systems consisting of buried pipelines and concentrated structures

- A description of various hazards affecting the operation of water and wastewater systems

- A discussion of social needs and infrastructure interdependencies, (such as transportation, fuel, and power), related to water and wastewater systems

- Examples of performance goals and matrix of water and wastewater systems

- Observed damage to components of water and wastewater systems from the most recent earthquake/tsunami events

- Regulatory agencies and existing codes and standards

- A brief discussion of resilience assessment methodology

- A list of recommendations

Dr. $\mathrm{Yu}$ indicated that the sole purpose of the listed recommendations was to stimulate discussion among the workshop participants. From the observed practice in recent earthquakes, Dr. Yu raised some questions, and also would like to get input on regulatory agencies' expectation on the post-event level of services and regulatory compliance for water and wastewater systems. In addition, Dr. Yu also raised a question on roles/responsibilities of public health officials or wastewater service providers related to removing sewage from homes right after an event - who should provide portable potties to a disaster affected community.

The facilitator went through the handout, and used a list of specific questions to start the discussion. A question was raised on how much flexibility there was in terms of the overall 
methodology and performance matrix. Dr. Yu, Ms. Sheldon, and Dr. Kuligowski indicated that the chapter is still in draft, and the authors are open to ideas and comments.

The first question asked of the participants was:

"What key elements and characteristics would you find to be the most useful in a Disaster Resilience Framework that is intended to guide community planning for disaster resilience for the water and wastewater sector?"

As can be seen from Table 37, there was a lot of useful input provided by the participants. The participants immediately expressed their concern that the current chapter is mainly focused on earthquakes and tsunamis. The participants felt it is important to broaden the resilience scope and take an all-hazards approach. The chapter needs to expand to include flood, hurricane, power outages, and other hazards. Some of them will not necessarily cause physical damage to components of water and wastewater systems, but they will affect the services and functions of water and wastewater systems. Some felt it is critical to consider alternate energy sources for extended periods, and raise the standard for backup/standby power systems to withstand fuel supply disruptions, including on-site renewable options for continuity of treatment facilities. It is also important to address transportation access to facilities as a resilience measure for staff, fuel, etc. Alternate plans for waste transportation need to be considered.

Disaster resilience for water and wastewater systems is not as clear cut as other lifeline sectors. The sector chapter should include water quality or regulatory compliance. It was suggested that the chapter refine the assumption that rural areas could deal without water longer than urban areas because the heart of the issue is no water, no flush.

Some participants felt it is reasonable to accept a certain level of loss because it is not feasible to be $100 \%$ resilient.

Community resilience planning should be region specific to: (1) reflect hazard scenarios specific to that area, (2) consider population density, critical infrastructure utilities, and facility location, and (3) address functioning capacity evaluation at different scenarios. It is necessary to consider where the help comes from - within the impacted area or outside the impact area. It is important to look at redundancy at a regional level as opposed to just community-specific.

The group stated that the framework should explain resilience planning linkage with PPD-8 and 21 to avoid confusion and unnecessary repetitive planning efforts in the water and wastewater sectors. It is important to appropriately recognize some existing standards such as AWWA J-100 Risk and Resilience Management for Water and Wastewater Systems. 
Table 37. Key Elements and Characteristics for Disaster Resilience Framework in Water and Wastewater Sector

\section{Q1: What key elements and characteristics would you find most useful in a disaster resilience framework that is intended to guide community planning for disaster resilience for water and wastewater sector? ("What would help you the most?")}

- Expand beyond earthquakes to include flood, power outages, wind (current incidents)

- Include:

- Floods - drought

- Hurricanes

- Storm surge

- Tornado

- Changes in precipitation (cc)

- Changes in temperature (cc)

- SCR - (cc)

- Capability /performance should be determined locally $\rightarrow$ recovery time only one dimension and misses acceptable loss

- Take all hazards approach, resilient to manmade and natural disasters

- Include issues with smallerscale systems (wells, cesspools) because sometimes they are applicable to water quality

- Include green infrastructure in the catchment basin of the collection system as resilience measure

- Address hazard events from a chronic v. episodic. Resilient systems to withstand frequent shallow coastal flooding different from scaled episodic events

- Potential measures/concepts for incorporating resilience, particularly those that have multihazard application
- We need to define the spectrum of water related problems first. Then, we need to look at resilience as a continuum leading to irreversible situation. Then we need to develop a system of approach.

- Alternate plans for waste transportation

- Alternate energy sources for extended periods of time

- Water and wastewater industry (regional) conferences focusing on emergency plans

- Assess facilities, particularly coastal low elevation, as part of a service network where resilience measures may entail network solutions, investments

- Refine assumption that rural could deal without water longer - issue is no water, no flush

- Recognize existing standards

- ANSI/AWWA, G430 - Security Operations

- J100 - Risk/Resilience

- G440 - Emergency Preparedness Practice

- Manuals of Practice

- Do no harm

- Address transportation access to facilities as a resilience measure for personnel, fuel, etc.
- Region/state/location specific 1. Identify: Population density, critical infrastructure and utilities, and facility location

2. Highlight and access possible scenarios specific to that area, i.e., flooding, hurricane, storms, fires, earthquakes, tornados

3. Functioning capacity evaluation at different scenarios

- Where should help come from? Within the impact area, or outside the impact area?

- Core threats - worst case local decision (see J100)

- Natural - earthquake, tornado, wildfire, flood, ice

- Malevolent - cyber, terrorism (physical)

- Accident

- Dependency

- Need linkage with PPD-8 and 21 capabilities, concepts in National Response Framework National Mitigation Plan, National Preparedness Goals, etc.

- Raise standard for backup power system to withstand fuel supply disruptions, including on-site renewable options for continuity of treatment facilities

After asking what should be included in the Water and Wastewater Sector of the framework, the second question asked of the participants was: 
"Who should define the performance goals and make the decisions for a community or regional disaster resilience plan in the water and wastewater sector?"

As seen in Table 38, the input for this question varied. Some felt that no one should determine performance goals because performance goals are system/geographic dependent. Some felt that performance levels would be difficult to standardize nationally, and would distract from base capacities such as those considered in the Utility Resilience Index (URI).

Most of the participants felt that key decision makers, including water utility leaders, emergency managers, planners, civil engineers, and regulatory agencies, should define the performance goals. It is critical to start at a local level, have community buy-in, and get lowest level government possible involved in the process.

Table 38. Parties Responsible for Determining Performance Goals for Water and Wastewater Sector

Q2: Who should define the performance goals and make the decisions for a community or regional disaster resilience plan?

- Who should determine performance goals: No one! System/geographic dependent $\rightarrow$ qualitative examples

- Performance levels are difficult to standardize nationally based on scale/intensity, distracts from base capabilities such as those in URI

- Key decision makers

- Start at local level

- Lowest level government possible

- Community buy-in

- Emergency managers, civil engineers and planners

- Joint effort between regulatory agency (e.g., NJDEP) and those in the water and wastewater sectors; EPA $\rightarrow$ NJDEP $\rightarrow$ wastewater treatment within regulated parts (??)

- Water utility

As a follow-up to the second question, the third question asked of the breakout group participants was:

"Within the water and wastewater sector, at what level and sublevel should we be assigning performance goals and targets for disaster resilience for the expected event? Should this be at a relatively high level, or are sublevels important? Should the same groupings be used for routine and extreme events?"

To supplement the question asked, the facilitator explained that understanding the appropriate levels is important because they will be used to develop guidance for performance in the framework later on. The facilitator developed a matrix, shown in Table 39, showing a high-level category plus subcategories based on the chapter, and initiated discussion on the performance targets for water and wastewater systems - restore X\% services for Y number of people within Z timeframe. 
The group agreed that we should have performance targets for a community to strive for, and that performance goals should be set at a high level. Some discussion was devoted to whether we need to go down to sublevels for performance targets. Some felt that some central components of the system should remain functional after an event. Dr. Yu shared his perspective that a performance target/level for a component should be tied to specific hazard levels, and a timeframe for restoration of service is what a community cares about most. For water systems, we need to consider life-safety, (for staff working inside the facilities and for firefighting), and public health, (e.g., provide water to healthcare facilities). For each hazard level, the timeline for restoration of services is individual for each community based on their social/business needs.

Restoration of water supply can be the most crucial element and it may need to be restored before anything else if there is extensive damage to the system and restoration of normal service is expected to take a long time. Thus, for extreme events, a separate performance goal for water supply may be warranted. Some participants felt that having sublevel performance might help prioritize the most important system components.

Some participants were very concerned that the decisions made by participants, (mostly from federal agencies, although unintentionally), might not reflect actual community needs, thus becoming less useful. They were especially concerned that, in practice, there is inadequate inter-agency collaboration. We need to coordinate with other federal agencies to avoid highly repetitive work for the Disaster Resilience Framework.

\section{Table 39. Level of Assigning Performance Goals for Disaster} Resilience in the Water and Wastewater Sector

Q3: At what level and sublevel should we be assigning performance goals and targets for disaster resilience for the expected event? Same groupings for routine and extreme event?

\begin{tabular}{|c|c|c|c|}
\hline $\begin{array}{l}\text { Waste/Wastewater } \\
\text { System Component }\end{array}$ & Routine & Expected & Extreme \\
\hline $\begin{array}{l}\text { - Water Systems } \\
\text { - Supply } \\
\text { - Transmission } \\
\text { - Transmission pipelines } \\
\text { - Distribution pipelines } \\
\text { - Treatment plants } \\
\text { - Pumping stations } \\
\text { - Storage }\end{array}$ & $x$ & $x$ & $\begin{array}{l}\text { X } \\
\text { X (supply) }\end{array}$ \\
\hline $\begin{array}{l}\text { Wastewater Systems } \\
\text { - Collection } \\
\text { - Pumping } \\
\text { - Treatment } \\
\text { - Effluent discharge }\end{array}$ & $x$ & $x$ & $x$ \\
\hline
\end{tabular}


The fourth question asked of the participants was:

"Assume that your desired end-state is a well-defined disaster resilience framework which enables the community to set targets for the built environment. What do you think will be the primary barriers, challenges, or impediments to creating and executing your disaster resilience framework in the water and wastewater sector, from a community, personal experience, regional, or national perspective?"

As shown in Table 40, participants provided a significant amount of input, and identified barriers and challenges that would potentially affect creation and execution of a disaster resilience framework. The most significant barriers and challenges agreed upon by the participants are: (1) lack of coordination with other providers to discuss lifeline interdependencies, (2) lack of understanding value of resilience, (3) lack of involvement of business and end users, (4) lack of coordinated standards and tools, and (5) utility providers' liability concern.

The participants input was broken down into several categories, including codes and standards, funding, organizational barriers, regulatory, social needs, utility provider barriers, and the political/community environment.

Participants were uncertain if codes for certain components of the systems will ever consider disaster resilience. Furthermore, guidance will be needed as to how resilience can be implemented into the codes and standards.

As for all sectors, funding is a key issue that may prevent implementation of the framework. Resources must be set aside for implementation and support analysis, which is difficult to do with budgets that have many other priorities to balance. Since education/outreach is needed to promote adoption across an entire sector or multiple sectors, funding for training asset owners is needed.

From an organizational perspective, lack of regional cooperation and authority is expected to be a barrier. The participants felt there is a lack of prioritization/hierarchy, and clarity as to who is in charge. Furthermore, since communities do not own the water infrastructure, (i.e., it is shared/regional infrastructure), it will be difficult to get stakeholders at the regional level involved in development of resilience plans for small communities. The constant changes in regulations and Clean Air Act (CAA) disincentives to invest in backup/standby power were also listed as concerns.

The participants felt that there is a lack of understanding of the value of resilience, which is important because building resilience into infrastructure requires capital investment. We need to educate the public to understand the value of resilience so that water/wastewater providers can justify their additional investment and pass the cost down to their customers. 
The participants pointed out that the utility providers will have liability concerns in setting performance goals and evaluating their infrastructure. Once a water or wastewater service provider identifies deficiencies in their system to meet resilience performance targets, they are concerned with potential litigation for not taking timely action to correct their deficiencies if a disaster takes place before they are able to correct the deficiency.

Table 40. Barriers and Challenges to Executing Implementation of the Disaster Resilience Framework in the Water and Wastewater Sector

Q4: What do you think will be the primary barriers/challenges or difficulties to creating and executing your disaster resilience framework/plan, from a community, personal experience, regional or national perspective? Note: bold red text indicates greatest barriers/challenges

- Lack of regional cooperation and authority - absence of prioritization/ hierarchy

- Locals do not control power, regional water*, shared/regional infrastructure ${ }^{*}$ Riverine, coastal

- Money and implementing plans plans tend to sit on shelves; capacity

- Communication between and/or buyin from different levels of government utilities, agencies, the public, etc.

- Unintended consequence of not meeting performance standard and liability

- Financial resources to support analysis

- Need better defined nexus with daily operations, e.g., link asset management to risk management

- Wide adoption across sector - Education/outreach

- Funding for training to asset owners

- San Francisco was a great example, but how get other cities/towns to create own version of disaster resilience?

- Uncertain if codes for certain components will get to disaster resilience - may need guidance too
- Money

- Constant change in roles

- Constant change in regulations

- Every party has a different vision

- State, federal, local all can have different rules and regulations

- Who is in charge? No clear organizational structure

- All situations are different and changing

- Public participation
- Lack of understanding value of resilience

- Lack of coordination of with other providers to define/discern lifeline in interdependency

- Liability concern

- Lack of standards and tools

- Lack of involvement of business and end users

- Federal programs only subsidize replacement of existing structures, not improvements

- Regulatory

- CAA disincentive to invest in backup power

- FEMA - replacement vs. upgrade

- Fear of losing tax base due to high vulnerability to sea level rise and limited options

- Not taking into account vulnerabilities or needs of a community

The continual changes in the political environment also pose a challenge to implementation of the framework. Different parties have different visions, priorities (and thus funding), and roles in their influence on initiatives.

The fifth, sixth and seventh questions were introduced together since they were interrelated. The questions asked of the participants were: 
This publication is available free of charge from: http://dx.doi.org/10.6028/NIST.GCR.14-979

"What new/updated/improved standards, codes, models, practices, and thresholds/performance goals are needed to support effective disaster resilience in the water and wastewater sector?

What are the knowledge needs, (e.g., data or models or guidance), or gaps in your community relative to disaster resilience in the water and wastewater sector?

What evaluation methods, specific to the water and wastewater sector, are needed to help determine effectiveness in community disaster resilience?"

After the facilitator introduced questions \#5, \#6, and \#7 Dr. Yu briefly reviewed resilience evaluation methods. For a disaster at a given hazard level, we need to perform necessary assessment of existing systems to determine where we are today, considering co-location of water and wastewater pipelines with bridges, (when pipelines cross over rivers and canyons), and interdependency of operation of water and wastewater systems with other lifeline sectors, (i.e., sequential recovery and restoring of lifeline sectors). During the evaluation process, we can identify what is needed to determine the timeframe of restoration of services based on the system's current conditions. Based on the resilience targets set by a community, we need to identify standards, practices, and necessary steps to narrow/close resilience gaps for water and wastewater systems. The input from participants regarding the fifth question, shown in Table 41, can be categorized into codes/standards, practices, evaluation methods/tools, and knowledge needs/gaps.

The codes/standards/models include:

- AWWA M19 Emergency Planning for Water Utilities

- Planning for an Emergency Drinking Water Supply

- Emergency Power Supply for Water (Systems)

- Process Control System Security

- ANSI/AWWA G430 Security Practices for Operations and Management

- G440 Emergency Preparedness Practices

- J100 Risk/Resilience Management (including the Utility Resilience Index)

Some of the practices identified by the participants include updated Flood Insurance Rate Maps (FIRMs), accurate flood maps, and lessons learned from documented best practices. The group also discussed the need to track and assess resilience capacity of your community over time and how well your community responds to a disaster before, during, and after that disaster. The community could also use the data collected to calibrate resilience assessment, prediction, and projection before and after resilience improvements.

The group also identified and discussed a number of tools that can be used, including the Utility Resilience Index (URI) included in AWWA J100, the Vulnerability Self-Assessment Tool (VSAT) by the Environmental Protection Agency (EPA), and the Program to Assist Risk \& Resilience Examination (PARRE) by Applied Engineering Management Corporation (AEM). 
The group felt that the knowledge needs/gaps include:

- Guidance for reducing long-term or future risk that changes

- Standards or guidelines for retrofit of pipelines, (e.g., seismic retrofits)

- Interdependency modeling

- Standard sea level rise (SLR) projections

- Incentives for improved infrastructure upkeep and technology

Table 41. Improvements to Current Standards, Codes, Models, and Practices Needed to Support Disaster Resilience in the Water and Wastewater Sector

\section{Q5. What new/updated/improved standards, codes, models, practices/guidance and thresholds/performance goals are needed to support effective disaster resilience?}

- Most recent data available

- Utlize new/resilient measures used in similar disasters/situations

- Updated FIRMS (flood insurance maps)

- Accurate flood maps

- Guide for disaster elevated design levels

- Lesson learned document best practices
Many existing standards, codes, tools, etc. (all bullets in this column):

- Evaluation method existing J100 standard

- Tools: VSAT - (EPA) PARRE - (AEM)

- Utility resilience index (URI) in $\mathrm{J} 100$

- ERP, NIMS, Emergency Power, Min Daily Demand, Staff, Mutual Aid, BCP, Bond Rating, Community unemployment and income

- M19 - "Emergency Planning for Water Utilities"

- "Planning for an Emergency Water Supply"

- "Emergency Power Supply for Water..."

- "Emergency Water for Hospitals/Healthcare"

- "Process Control System Security"

- ANSI/AWWA ( ${ }^{*}$ Safety Act)

- *G430 - Security Practices for Operations and Management

- G440 - Emergency Preparedness Practices

- J100 - Risk/Resilience Management - includes Utility Resilience Index (URI)
- Standards, codes and guidance

- Encourage and incentivize green infrastructure technology from homeowner up

- Enforcement illegal connections

- Incentivize building of new infrastructure to keep pace with demand and aging infrastructure

- Standardize SLR projection. Can be used to secure resiliency funding even without past damage.

- Guidance for reducing long-term or future risk that changes

- Standards or guidelines for seismic retrofit of pipelines. Seismic design of pipelines

- Interdependency modeling
- System of systems thinking needed 
When moving along to the sixth question, the participants input, summarized in Table 42, can be categorized into education, data, guidance, and gaps.

The participants felt that education is an important component of the framework development and implementation process. There will be a needed period of knowledge transfer through training/support. Just as we need to encourage the use of best practices, we need to discourage "bad" practices. Ensuring a clear definition of roles is imperative to the successful implementation of any framework.

The need for accurate and reliable data, (e.g., costs), is important to mitigate disaster impacts. For a community, (including service providers), to assess its needs, it must understand its social needs and infrastructure. The customers who are dependent on power for water supply must be identified. Furthermore, a complete asset inventory is needed to identify potential backflow system backups, Sea Level Rise (SLR), and flooding data.

The participants identified the need to know what scenarios communities should be dealing with, and the need to know the recovery and resilience metrics that should be used. To help address the guidance needed for communities, the participants felt that certain gaps could be addressed, including having community specific disaster preparedness plans, completing regional wastewater surveys, and information for climate projection on extreme events.

Table 42. Knowledge Needs and Gaps in Disaster Resilience for the Water and Wastewater Sector

\section{Q6: What are the knowledge needs (e.g., data, information) or gaps in your} community relative to disaster resilience in water/wastewater sector?

- Knowledge transfer - education/training support

- More utility participation in WARN - mutual aid and assistance

- Knowledge needs:

- What the insurance companies think?

- Accurate costs to mitigate disaster impacts

- Compare number of day(s) out of service, boil water, etc. - from event to event $\rightarrow$ percent should be lower $\rightarrow$ will be event dependent

- Education and sharing within communities, faciliites, agencies

- Knowledge

- Shared responsibilities (people have different strengths)

- New temporary roles, where needed

- Competing metrics and absence of baseline data for natural systems

- Need to know what scenarios we are dealing with first before deciding what data we need
- Knowledge needs:

- Recovery metrics

- Resilience metrics

- Asset inventory with elevations, ages, criticality

- Potential for backflow system backup

- SLR and flood localized data

- Have a community specific disaster preparedness plan

- Which customers are dependent on power for water supply

- Regional wastewater surveys (pre, current, post)

- Better (i.e., local, useful) precipitation. Infomration for climate projections of extreme precipitation

- Before any standards need a taxonomy of events and resulting metrics. Find out what exists.

- Educate the pbulic to stop "bad" practice land use policy and zoning

In response to the final question asked of the participants, the group identified and discussed a number of appropriate evaluation methods, as shown in Table 43. To determine the effectiveness 
in community disaster resilience, the participants felt we need to create models with sufficient data, (considering interdependencies with other lifeline sectors), to predict what is needed and what will be the outcome. We need to evaluate effectiveness of our preparation after a disaster occurs, and continue to improve our models and approaches. When making decisions on investment for disaster resilience, we need to perform cost-benefit analyses from a community's perspective, (explicitly considering indirect economic loss, health impact, and ecosystem benefits), as opposed to making decisions based on a cost-benefit analysis just from the utility service provider's perspective, thus optimizing our decisions based on community's global needs. Some participants felt that the AWWA J-100 methodology and its resilience index provide useful information to guide a community to build its disaster resilience.

Table 43. Evaluation Methods Needed Specific to Water and Wastewater Sector

\section{Q7: What evaluation methods, specific to water/waterwater sectors are needed to help determine effectiveness in community disaster resilience?}

- Cost-benefit analyses - updated methods $\rightarrow$ consider larger impact; WHEAT tool

- Create models with data to predict needs/outcomes

- Computer models

- Wait for storm/disaster you prep for, then evaluate after

- Technologies in mitigation

- Resilience Index J-100/M-19

- SF example evaluation

- Historical success

- How do you evaluate how "well" we did?

- Consistent revisit of risk assessment; revised asset/threat pair based on current and future conditions(scenarios)

- Update/practice ERP

- Monetization of ecosystem benefits

- Health impacts assessment (CSO exposures from flood)

At the conclusion of the afternoon breakout session, the group reviewed the questions and responses captured during the day. The group was asked to select three to five key takeaways from the session. The general consensus of the group is summarized in Table 44. 
This publication is available free of charge from: http://dx.doi.org/10.6028/NIST.GCR.14-979

Table 44. Key Takeaways from the Water and Wastewater Systems Sector Breakout Session

\section{Water and Wastewater Breakout Session Key Takeaways}

- The group needs more utilities and other local level representatives; the group consisted mainly of federal agency employees.

- This framework and its developers must coordinate with other federal agencies that are working on disaster resilience, and take into account and utilize work that has already been done; we should not be reinventing the wheel and/or duplicating efforts.

- The Framework must address all hazards.

- Restoration of service is the only performance metric that really matters.

- Whenever possible, plans and decisions should be made at the local level; local plans should address hazards and risks specific to the area. 


\section{Breakout Session \#7: Disaster Resilience Standards Panel Charter}

As was done for the other breakout sessions, both a morning, (10:45 a.m. - noon), and afternoon, $(2: 30-4: 30$ p.m.), breakout session were held to get input from the stakeholders in attendance. However, this final breakout was different than the other sessions because it did not focus on an individual sector of the framework. Rather, the objective of this session was to provide input that will help NIST develop a Disaster Resilience Standards Panel (DRSP) Charter that will help articulate the mission, vision and other key aspects of the Panel.

During the morning session, the participants were divided into smaller groups of 3-4 people to develop a potential mission and vision statement for the DRSP. In developing the mission statement, the groups were asked to consider the following questions regarding the function of the DRSP:

1. What will the DRSP do for U.S. Community Disaster Resilience?

2. What core values will the DRSP stand for?

For development of the vision statements, the groups were asked to consider the following questions:

1. What will the DRSP's activities look like in the future?

2. What will look different about disaster codes and standards as a result of the DRSP'S involvement?

Each of the groups received a card to write their mission and vision statements on for presentation to the rest of the group. Within each small group, a writer and speaker were selected.

The small groups spent the entire morning session discussing what they envisioned for the DRSP and coming to an agreement, within their groups, of what the mission and vision statements should be for the DRSP. The groups had very active discussions and were asked to complete their statements before the break, but encouraged to continue the discussion over lunch.

At the start of the afternoon breakout session, each of the groups presented their mission and vision statements for the DRSP. Their mission and vision statements were then posted on a storyboard for all participants to observe.

Group \#1 provided a mission statement of, "Make U.S. communities the most resilient in the world." The core values they expected to be associated with the DRSP were honesty and integrity. Group \#1 developed the following four aspects that they wanted included in a vision statement:

- Alignment to influence applicable codes and standards 
- Promoting best practices \& engages learning to drive towards a resilient community.

- Vetting and validation of codes/standards

- Guidance in pilots for resilient solutions.

Group\# 2 provided a mission statement of, "Facilitate cross-sector communication and invite innovation for U.S. resilience policy." Their vision statement was, "Add value to community resilience through cross-sector collaboration and enhancement of the built environment."

Group \#3 took a different approach and did not provide specific mission and vision statements for the DRSP. Instead, the group identified and provided the points it felt were most important for the DRSP, including creating and maintaining a process to:

- Create a demand for resilience

- Identify the impediments to resilience

- Facilitate closing the gaps toward resilience

Group \#3 also identified the core values it felt were important as collaboration, change oriented, inclusive, and experimentation.

Group \#4 developed a mission statement of, "DRSP will identify gaps and guide development of national policies, standards, and codes to assure resilient communities and a resilient society." The group did not develop an explicit vision statement. However, it did identify the attributes/qualities it felt the DRSP must have, including authoritative, high profile, inclusive/multi-stakeholder, develops norms, sensitive to community needs, and social goals based. Group \#4 also stated that one of the goals of the DRSP should be to enhance, (rather than replace), existing codes and standards.

Once all of the sub-groups presented their ideas, the whole group of participants worked together to identify commonalities and keywords in their mission and vision statements. The breakout facilitator, from Energetics Incorporated, recorded the main points and commonalities of the subgroups as shown in Table 45.

When discussing the keywords and qualities of the DRSP, the group identified and agreed that the DRSP should also "provide leadership" and "advocate for resilience." There was some discussion within the group of whether the DRSP should provide leadership itself or simply be an advisory panel. It was quickly decided that in order to achieve its goals and accomplish what the group envisioned, the DRSP must take an active leadership role in promoting resilience. 
Table 45. Breakout Group Mission and Vision Statements

\section{Session I: Mission and Vision Statements \\ Note: bold red text indicates common themes}

Q1: What will the Disaster Resilience Standards Panel (DRSP) Charter do for U.S. community disaster resilience? What core values will the DRSP stand for?

- Make the U.S. communities the most resilient in the world

- Core Values

- Collaboration

- Change-oriented

- Inclusive

- Experimentation

- DRSP will identify gaps and guide development of national policies, standards and codes to assure resilient communities and a resilient society

- Facilitate cross-sector communication and invite innovation for U.S. resiliency policy
Q2: What will DRSP's look like in the future? What will look different about the disaster resilience standards and codes arena as a result of DRSP's involvement?
- Community centric

- Provides advocacy for resilience

- DRSP

- Authoritative

- High profile

- Inclusive/multi-stakeholder

- Develops norms

- Sensitive to community needs

- Enhances/not replaces existing standards/codes

- Social goals-based

- Create and maintain a process to

- Create DEMAND for resilience

- IDENTIFY the impediments to resilience

- FACILITATE closing the gaps towards resilience

- Add value to community resilience through crosssector collaboration and enhancement of the built environment

- Activity examples

- Alignment to influence applicable codes and standards

- Promoting best practices and ongoing learning to drive towards a resilient community

- Vetting and validation of codes/standards

- Guidance on pilots for resilience solutions

When identifying keywords in their mission and vision statements, the group agreed that the following four keywords should be included in the final mission and vision statements for the DRSP:

- Leadership

- Facilitation

- Cross-sector

- Collaboration

After identifying keywords to be included in the mission and vision statements, the participants were asked to identify three objectives of the DRSP that would allow it to accomplish its mission. Each member of the group was provided with cards to write down individual objectives of the DRSP. Once the participants wrote down the objectives they envisioned for the DRSP, each participant was asked to share their objectives. The participants provided a lot of great input 
for the objectives of the DRSP including that they want the DRSP to further develop the framework, produce broad guidelines and standards, create a demand for resilience, have frequent two-way conversations with a broad range of stakeholders, sponsor resilience pilots, and develop resilience metrics and tools. Table 46 shows the range of ideas generated by the breakout group attendees.

After all of the ideas were shared, each participant was provided with three orange "dots" to vote on the objectives that they felt were most important to the success of the DRSP. As seen in Table 46 , the following were identified by the participants as the most important objectives of the DRSP:

1. Create a demand for resiliency

2. Have frequent conversations with cross-sector stakeholders

a. Need to both listen to and advocate for the stakeholders

3. Use spiral, (i.e., cyclical), development of innovation in resilience thinking and adoption

4. Develop resilience metrics so that the individual silos, (i.e., sectors) can be quantified 
Table 46. Breakout Group Objectives for DRSP to Fulfill its Vision

Session II: What objectives, if achieved, will enable the Disaster Resilience Standards Panel to fulfill its vision? A successful DRSP will have accomplished

Notes: • indicates number of votes; red bold text indicates top goals/objectives; create a demand for resilience was viewed as a broad goal that gained the most votes; the objectives in the column help to contribute to this goal

\begin{tabular}{|c|c|c|c|}
\hline $\begin{array}{l}\text { Publications, } \\
\text { Guidelines, Metrics }\end{array}$ & Membership & $\begin{array}{l}\text { Create a demand for } \\
\text { resiliency }\end{array}$ & Outcomes \\
\hline $\begin{array}{l}\text { - Resilience metrics } \\
\text { - be able to quantify } \\
\text { various "silo's" } \\
\text { contribution to } \\
\text { resilience••(3) } \\
\text { - Cross sector } \\
\text { (infrastructure } \\
\text { systems) minimum } \\
\text { standard for resilience } \\
\text { (codeplus) developed } \\
\text { - Resilience framework } \\
\text { validated and updated } \\
\text { - } \\
\text { - Framework } 2.0 \\
\text { - Tangible success } \\
\text { measures in health } \\
\text { and economics } \\
\text { - Framework } \\
\text { implementation } \\
\text { guidelines for } \\
\text { communities } \\
\text { developed } \\
\text { - Establish linkages } \\
\text { to FEMA mitigation } \\
\text { funding (\$) } \\
\text { - Templates for } \\
\text { standards and codes } \\
\text { developed } \\
\text { - Performance } \\
\text { objectives and levels } \\
\text { developed } \\
\text { - Framewuence } \\
\text { published } \\
\text { - Guidelines } \\
\text { published } \\
\text { - Brand standard } \\
\text { (e.g., ISO) } \\
\text { - Regional/Communit } \\
\text { y } \\
\text { (interdependencies, } \\
\text { public benefits, } \\
\text { interests) }\end{array}$ & 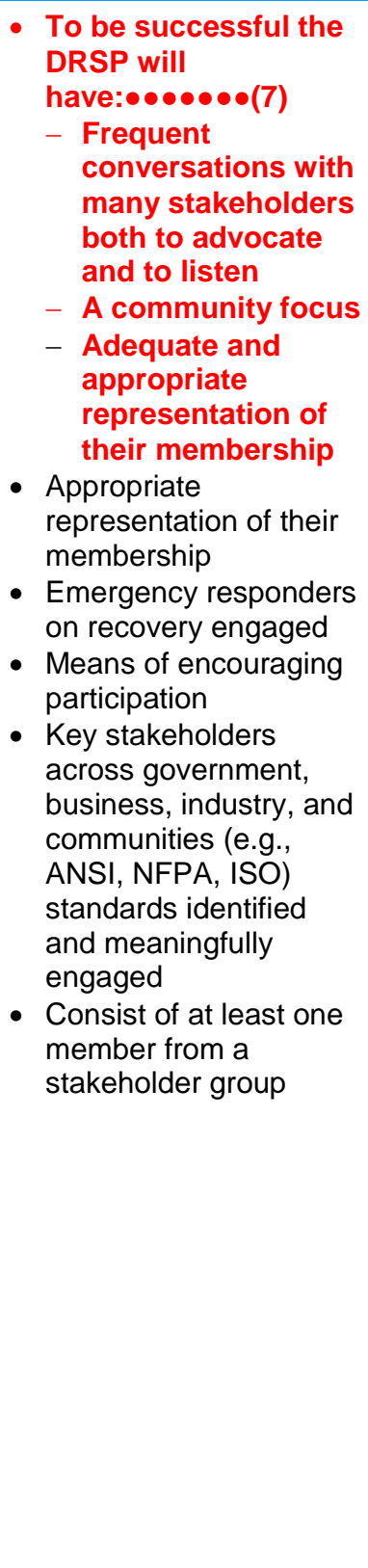 & 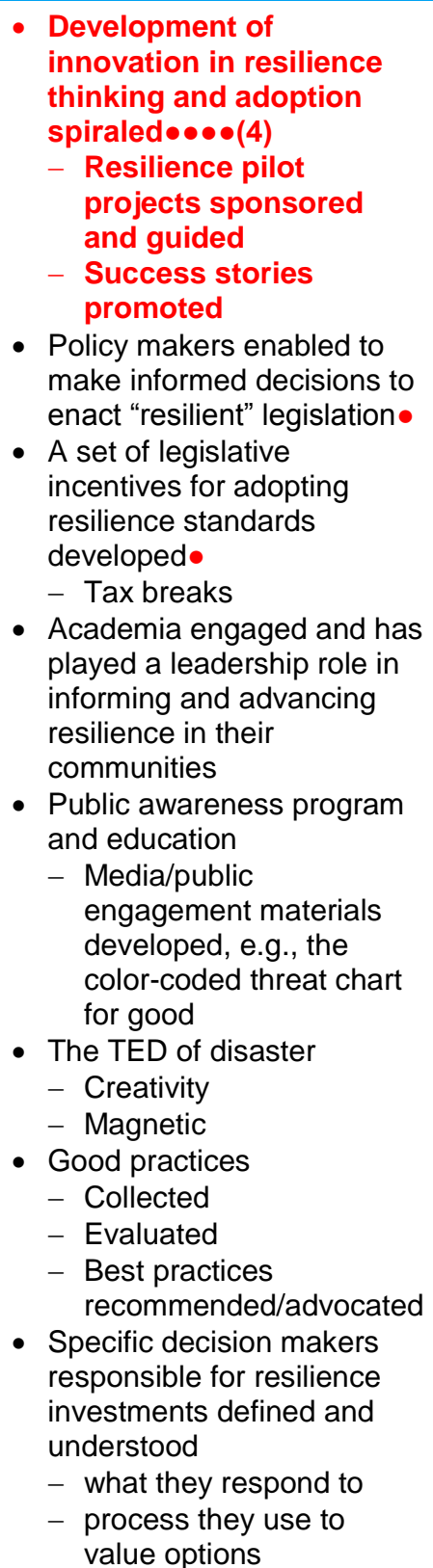 & $\begin{array}{l}\text { - The cost-benefit of } \\
\text { resilient } \\
\text { development- } \\
\text { environmental/social/ } \\
\text { economic is } \\
\text { understood } \\
\text { - Individuals and } \\
\text { communities better } \\
\text { understand how } \\
\text { resilient they are (or } \\
\text { are not!) } \\
- \text { e.g., scorecards? } \\
\text { - How to improve } \\
\text { existing } \\
\text { infrastructure/building } \\
\text { stock addressed }\end{array}$ \\
\hline
\end{tabular}


Table 47. Breakout Group Objectives for DRSP to Fulfill its Vision (Continued)

\begin{tabular}{|c|c|c|c|}
\hline \multicolumn{4}{|c|}{$\begin{array}{l}\text { Session II (continued): What objectives, if achieved, will enable the Disaster } \\
\text { Resilience Standards Panel to fulfill its vision? A successful DRSP will have } \\
\text { accomplished } \\
\text { Note: • indicates number of votes }\end{array}$} \\
\hline $\begin{array}{l}\text { DRSP Long-term } \\
\text { Sustainability }\end{array}$ & DRSP Recognition & $\begin{array}{l}\text { DRSP Solutions } \\
\text { Approach }\end{array}$ & $\begin{array}{c}\text { DRSP } \\
\text { Management } \\
\text { Principles }\end{array}$ \\
\hline 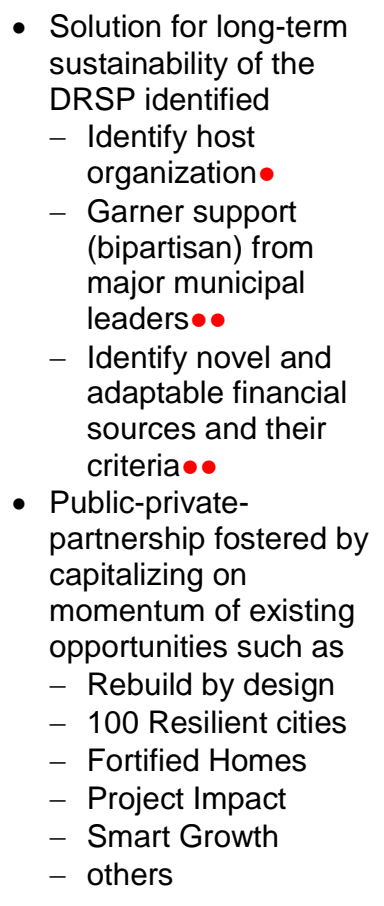 & $\begin{array}{l}\text { - Substantial public } \\
\text { recognition (i.e., } \\
\text { presidential) of the } \\
\text { panel and its mission } \\
\text { - Has served as an } \\
\text { independent trusted } \\
\text { resource for resolving } \\
\text { built code/zoning } \\
\text { conflicts }\end{array}$ & $\begin{array}{l}\text { - Apply principles of } \\
\text { "environmental psychology" } \\
\text { - Create synergy and } \\
\text { innovative solutions } \\
\text { between sustainability and } \\
\text { resilience } \\
\text { - Multi-disciplinary and multi- } \\
\text { sector and multi-agency } \\
\text { solutions } \\
\text { - System-based solutions } \\
\text { and recommendations } \\
\text { - Fully coordinated systems } \\
\text { on regional level, local level } \\
\text { and federal level (?) } \\
\text { - Be careful of equities of } \\
\text { diverse communities }\end{array}$ & $\begin{array}{l}\text { - Employ principles of } \\
\text { Blue Ocean } \\
\text { Strategy: Four } \\
\text { Actions } \\
\text { - Eliminate } \\
\text { - Reduce } \\
\text { - Raise } \\
\text { - Create } \\
\text { - Develop project } \\
\text { management plan to } \\
\text { address all 10 } \\
\text { Project Management } \\
\text { Institute knowledge } \\
\text { areas } \\
\text { - Integration } \\
\text { - Scope } \\
\text { - Time } \\
\text { - Cut } \\
\text { - Quality } \\
\text { - Human resources } \\
\text { - Communication } \\
\text { - Risk } \\
\text { - Procurement } \\
\text { - Stakeholders }\end{array}$ \\
\hline
\end{tabular}

After the participants completed voting, the group agreed that the DRSP must address the community-centric concept as well.

At the conclusion of the afternoon breakout session, the group reviewed the questions and responses captured during the day. The group was asked to select three to five key takeaways from the session. The general consensus of the group is summarized in Table 48. 
This publication is available free of charge from: http://dx.doi.org/10.6028/NIST.GCR.14-979

Table 48. Key Takeaways from the Disaster Resilience Standards Panel Charter Breakout Session

\section{Disaster Resilience Standards Panel Charter Breakout Session Key Takeaways}

- An overarching goal for the Disaster Resilience Standards Panel (DRSP) should be to create a demand for resiliency.

- Activities to support this goal include spiraling innovation in resilience thinking and adoption through resilience pilot projects and success stories.

- To be successful, the DRSP will be community-focused, have frequent conversations with crosssector, multi-agency, multi-disciplinary stakeholders to advocate and listen, be community-focused, and have adequate/appropriate representation of their membership. 


\section{Closing General Session}

The closing session was led by Mr. Cauffman, who reviewed the key points identified throughout the day by several of the breakout groups and provided information to the audience regarding the next Disaster Resilience Workshop. The prepared text of Mr. Cauffman's remarks is provided here:

Thank you all again for attending today's workshop. We would like to review some of the key points from the breakout sessions today so everyone has an idea of what happened in each of the breakout groups. We will start with the building and facilities group, (Chapter 5 of the framework). The group's key takeaways are that we need to fill data gaps on existing buildings, and we need codes and standards with flexibility to experiment and try incorporating resilience. The group also wanted to see where the NIST-led effort fits in with the other resilience research efforts being led by other agencies and wants to be clear on the inter-agency coordination so efforts are not being repeated. The group's final key takeaway was that economic impacts are critical, meaning that the ability, (via tools and metrics), to estimate benefits and costs are needed.

The power/energy breakout key takeaways are that performance goals need to be established at sub-levels, (i.e., generation, transmission, distribution), and sub-sub-levels, (e.g., elements of transmission). The group also stated that there is a large need for more representatives at the workshops to show buy-in and make the effort successful, especially in such a complicated sector. The group also stated that the current model of paying by the kilowatt hour is a barrier to innovation and investing is resilience.

The communication and information systems breakout group felt that it is important to focus on service rather than specific technologies in developing the framework. In other words, the framework should focus on what needs to be addressed rather than how. Most importantly the participants agreed that face-to-face stakeholder collaboration is key to develop trust and understand the complexity of diverse stakeholder roles and responsibilities.

The Disaster Resilience Standards Panel Charter breakout group also provided a short list of key takeaways from the day. The group wants to create a demand for resilience, conduct frequent conversations with stakeholders, (similar to what we are doing with the workshop here today), encourage innovation in implementing resilience strategies, and develop quantitative metrics for resilience.

The water and wastewater breakout group also expressed the need to coordinate among all resilience planning/codes/standards, etc. with no duplication, and incorporate these efforts into the framework. The group would like to have the following question addressed in the framework: "Who is in charge to integrate all of these efforts?" In terms of systems analysis, the group wants to address the problem using a holistic approach rather than a sector-bysector approach. The group also expressed the need to look at redundancy on a regional level 
and not just community-specific.

As we mentioned this morning, the next workshop will be held on October 27-28, 2014 at the NCED Hotel and Conference Center in Norman, Oklahoma. That workshop will have a similar format to this one, but we will be further along in the development process of the framework and will include breakout sessions for the chapters that have not yet been developed.

Thank you all again for your participation, and we look forward to seeing you at future workshops! 